Prepared in cooperation with the National Park Service

\title{
Anticipated Effects of Development on Habitat Fragmentation and Movement of Mammals Into and Out of the Schoodic District, Acadia National Park, Maine
}

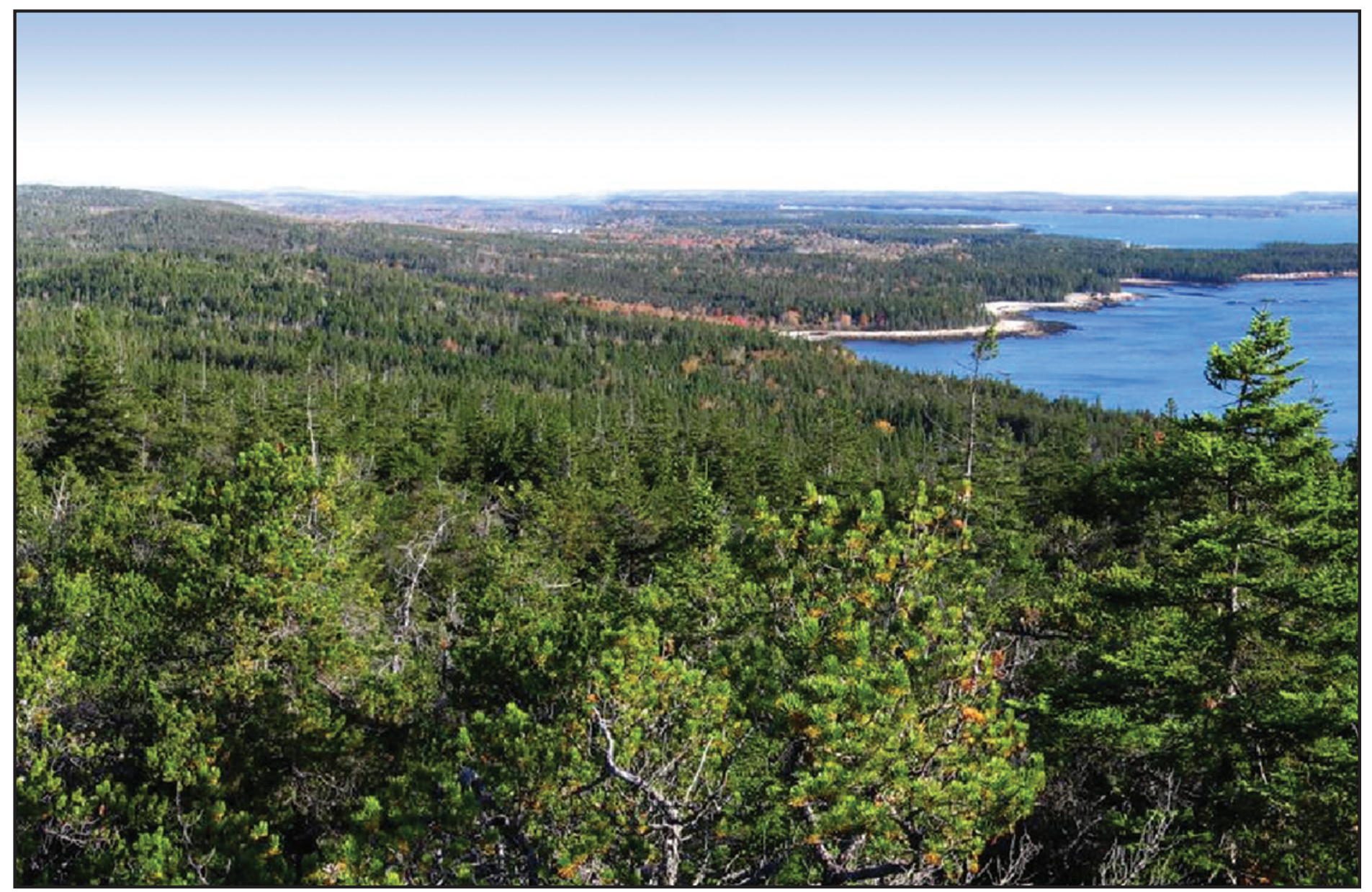

Scientific Investigations Report 2012-5149 
Cover. View from Schoodic Head, Acadia National Park. (Photograph by Todd M. Edgar, National Park Service.) 


\section{Anticipated Effects of Development on Habitat Fragmentation and Movement of Mammals Into and Out of the Schoodic District, Acadia National Park, Maine}

By Jason J. Rohweder, Nathan R. De Jager, and Glenn R. Guntenspergen

Prepared in cooperation with the National Park Service

Scientific Investigations Report 2012-5149 


\title{
U.S. Department of the Interior \\ KEN SALAZAR, Secretary
}

\author{
U.S. Geological Survey \\ Marcia K. McNutt, Director
}

U.S. Geological Survey, Reston, Virginia: 2012

For more information on the USGS - the Federal source for science about the Earth, its natural and living resources, natural hazards, and the environment, visit http://www.usgs.gov or call 1-888-ASK-USGS.

For an overview of USGS information products, including maps, imagery, and publications, visit http://www.usgs.gov/pubprod

To order this and other USGS information products, visit http://store.usgs.gov

Any use of trade, product, or firm names is for descriptive purposes only and does not imply endorsement by the U.S. Government.

Although this report is in the public domain, permission must be secured from the individual copyright owners to reproduce any copyrighted materials contained within this report.

Suggested citation:

Rohweder, J.J., De Jager, N.R., and Guntenspergen, G.R., 2012, Anticipated effects of development on habitat fragmentation and movement of mammals into and out of the Schoodic District, Acadia National Park, Maine: U.S. Geological Survey Scientific Investigations Report 2012-5149, 30 p. 


\section{Contents}

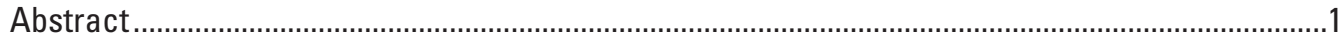

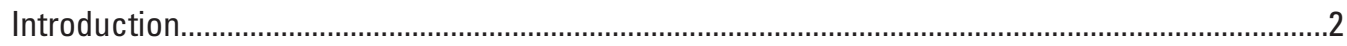

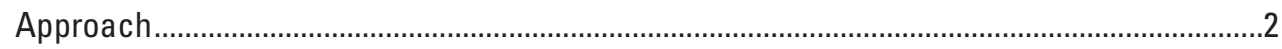

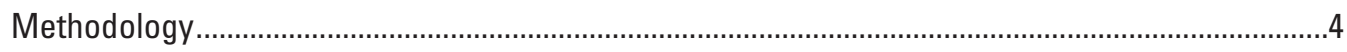

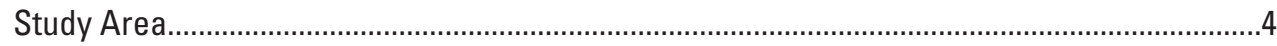

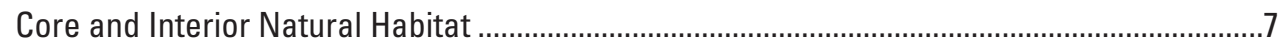

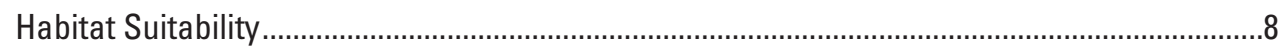

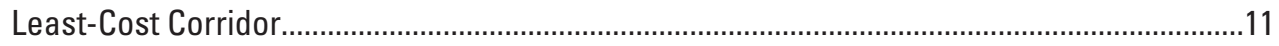

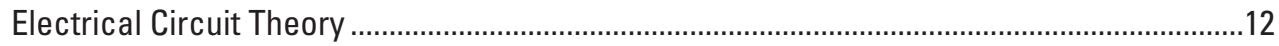

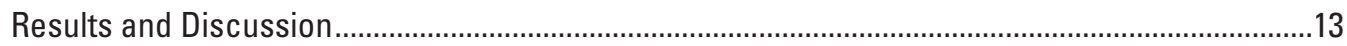

Core and Interior Natural Habitat ..................................................................................13

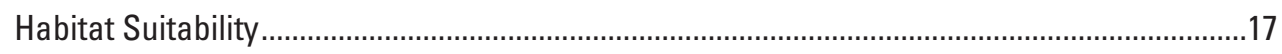

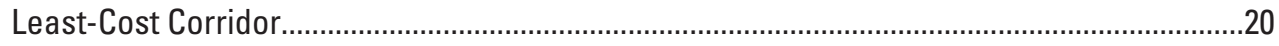

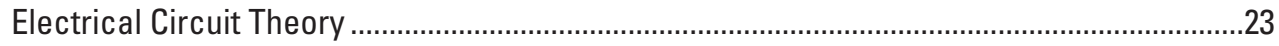

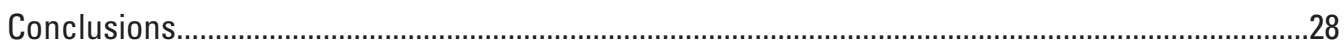

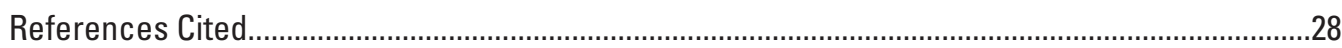

\section{Figures}

1. Map showing location of the Schoodic District of Acadia National Park and the Winter Harbor Holding Company parcel

2. Maps showing location of area of interest and Winter Harbor Holding Company (WHHC) parcel overlaid upon current land cover and an alternative land-cover scenario in which the WHHC parcel was reclassified as developed, open space

3. Maps showing three separate area of interest partitions used to summarize cost-distance and electrical circuit theory model results. .6

4. Reclassified land-cover map used for core and interior natural habitat analysis ............7

5. Diagram showing differences in how cost-distance and electrical circuit theory methods calculate habitat connectivity using a hypothetical landscape (adapted from McRae and others 2008).....

6. Maps showing differences in how cost-distance and electrical circuit theory methods calculate habitat connectivity using an actual landscape

7. Maps showing the distribution of core (100 percent natural) and interior (>90 percent natural) habitat under the current, undeveloped conditions for the Schoodic Peninsula

8. Maps showing the distribution of core (100 percent natural) and interior (>90 percent natural) habitat after reclassifying the Winter Harbor Holding Company parcel as developed. 
9. Graph showing the change in the proportion of natural habitat within the Schoodic District of Acadia National Park meeting the criteria of core (100 percent natural) and interior ( $>90$ percent natural) habitat

10. Maps showing habitat-suitability model results for bobcat without development of the Winter Harbor Holding Company (WHHC) parcel, with development, and the change attributable to development of the WHHC parcel....

11. Maps showing habitat-suitability model results for fisher without development of the Winter Harbor Holding Company (WHHC) parcel, with development, and the change attributable to development of the WHHC parcel.

12. Maps showing habitat-suitability model results for mink without development of the Winter Harbor Holding Company (WHHC) parcel, with development, and the change attributable to development of the WHHC parcel.....

13. Maps showing habitat-suitability model results for moose without development of the Winter Harbor Holding Company (WHHC) parcel, with development, and the change attributable to development of the WHHC parcel.

14. Graph depicting results of the 10 percent least-cost corridor overlap with the Winter Harbor Holding Company parcel using as source nodes high-quality habitat suitability areas north of U.S. Highway 1 and high-quality habitat suitability areas within the Schoodic District of Acadia National Park to the south ......20

15. Maps showing the cost associated with movement of bobcat between high-quality habitat suitability areas within Acadia National Park in the south and high-quality habitat suitability areas north of U.S. Highway 1 without development of the Winter Harbor Holding Company (WHHC) parcel, with development, and the change in cost attributable to development of the WHHC parcel

16. Maps showing the cost associated with movement of fisher between high-quality habitat suitability areas within Acadia National Park in the south and high-quality habitat suitability areas north of U.S. Highway 1 without development of the Winter Harbor Holding Company (WHHC) parcel, with development, and the change in cost attributable to development of the WHHC parcel

17. Maps showing the cost associated with movement of mink between high-quality habitat suitability areas within Acadia National Park in the south and high-quality habitat suitability areas north of U.S. Highway 1 without development of the Winter Harbor Holding Company (WHHC) parcel, with development, and the change in cost attributable to development of the WHHC parcel

18. Maps showing the cost associated with movement of moose between high-quality habitat suitability areas within Acadia National Park in the south and high-quality habitat suitability areas north of U.S. Highway 1 without development of the Winter Harbor Holding Company (WHHC) parcel, with development, and the change in cost attributable to development of the WHHC parcel

19. Graph showing differences in effective resistance between high-quality habitat suitability areas within Acadia National Park and high-quality habitat suitability areas north of U.S. Highway 1 for bobcat, fisher, mink, and moose with and without development of the Winter Harbor Holding Company parcel.. 
20. Maps showing changes to current density (a measure of the ease of animal movement) for bobcat between high-quality habitat suitability areas within Acadia National Park in the south and high-quality habitat suitability areas north of U.S. Highway 1 owing to development of the Winter Harbor Holding Company parcel

21. Maps showing changes to current density for fisher between high-quality habitat suitability areas within Acadia National Park in the south and high-quality habitat suitability areas north of U.S. Highway 1 owing to development of the Winter Harbor Holding Company parcel..

22. Maps showing changes to current density for mink between high-quality habitat suitability areas within Acadia National Park in the south and high-quality habitat suitability areas north of U.S. Highway 1 owing to development of the Winter Harbor Holding Company parcel...

23. Maps showing changes to current density for moose between high-quality habitat suitability areas within Acadia National Park in the south and high-quality habitat suitability areas north of U.S. Highway 1 owing to development of the Winter Harbor Holding Company parcel.

24. Maps showing changes to cumulative current density at the northern border of Acadia National Park summed across all four species (bobcat, fisher, mink, and moose) before and after development of the Winter Harbor Holding Company parcel

\section{Tables}

1. Habitat-suitability scores, based on land cover, for bobcat, fisher, mink, and moose

2. Costs associated with distance to roads with varying traffic volumes

3. The change in core (unfragmented) and interior (slightly fragmented) natural habitat area within the area of interest owing to development of the Winter Harbor Holding Company parcel.

4. Habitat-suitability model mean values, by area of interest partitions

5. Cost distance model-output values, by area of interest partitions, using high-quality habitat suitability areas north of U.S. Highway 1 and high-quality habitat suitability areas within the Schoodic District of Acadia National Park as source nodes.

6. Changes to mean current density (the equivalent of the flow of charge through a cell on the landscape, or ease of animal movement) following development of the Winter Harbor Holding Company parcel as it relates to animals moving between the Schoodic District of Acadia National Park and lands north of U.S. Highway 1 


\title{
Conversion Factors and Abbreviations
}

\begin{tabular}{lcl}
\multicolumn{1}{c}{ SI to Inch/Pound } & \multicolumn{1}{c}{ Bultiply } & \multicolumn{1}{c}{ To obtain } \\
\hline \multicolumn{1}{c}{ Length } \\
\hline millimeter $(\mathrm{mm})$ & 0.03937 & inch (in.) \\
meter $(\mathrm{m})$ & 3.281 & foot $(\mathrm{ft})$ \\
kilometer $(\mathrm{km})$ & 0.6214 & mile (mi) \\
kilometer $(\mathrm{km})$ & 0.5400 & mile, nautical (nmi) \\
meter $(\mathrm{m})$ & 1.094 & yard (yd) \\
\hline & \multicolumn{1}{c}{ Area } & \\
\hline hectare (ha) & 2.471 & acre \\
square kilometer $\left(\mathrm{km}^{2}\right)$ & 247.1 & acre \\
hectare (ha) & 0.003861 & square mile $\left(\mathrm{mi}^{2}\right)$ \\
square kilometer $\left(\mathrm{km}^{2}\right)$ & 0.3861 & square mile $\left(\mathrm{mi}^{2}\right)$ \\
\hline
\end{tabular}

Vertical coordinate information is referenced to the North American Vertical Datum of 1988 (NAVD 88).

Horizontal coordinate information is referenced to the North American Datum of 1983 (NAD 83).

\author{
Abbreviations used in this report: \\ ANP Acadia National Park \\ AOI area of interest \\ BWH Beginning with Habitat \\ MEGIS Maine Office of Geographic Information Systems \\ MELCD Maine Land Cover Data set \\ NPS National Park Service \\ NWI National Wetlands Inventory \\ WHHC Winter Harbor Holding Company
}




\title{
Anticipated Effects of Development on Habitat Fragmentation and Movement of Mammals Into and Out of the Schoodic District, Acadia National Park, Maine
}

\author{
By Jason J. Rohweder, Nathan R. De Jager, and Glenn R. Guntenspergen
}

\section{Abstract}

Most national parks interact with adjacent lands because their boundaries fail to encompass all regional habitats, species pools, and migration routes. Activities planned for adjacent lands can have adverse effects on park resources and visitor experiences. For example, fragmentation of adjacent habitat into smaller and more isolated remnants may influence the suitability of park habitat for a wide range of species and limit animal dispersal pathways, which may influence visitor experiences and park resources as well as the energy balance and population dynamics of the animals themselves.

In this study, we examined habitat fragmentation consequences owing to a planned 1,295 hectare development by Winter Harbor Holding Company (WHHC) adjacent to the Schoodic District of Acadia National Park (ANP), Maine. Specifically, we examined the effects of development on (a) core natural habitat area (a cross-habitat indicator of fragmentation), (b) the suitability of habitat for bobcat, fisher, mink, and moose, and (c) the movement of these four species between ANP and other nearby protected areas (species specific indicators of fragmentation). Our intention was to assist ANP staff in forecasting both the general and specific effects of development on natural habitat area, habitat suitability, and animal movement, which would allow them to develop suitable management alternatives.

Our cross-habitat analysis of core natural areas identified locations within the entire Schoodic Peninsula that are made up of only natural land cover (forest, grassland, shrubland, wetland, and other water bodies) for both the current land-use conditions and after development of the WHHC parcel. This general indicator of fragmentation revealed that development of the WHHC parcel would result in 1.6 to 8.7 times more loss in habitat meeting the "core" criterion as compared to overall habitat loss. The ratio increased with the spatial scale of analysis, indicating that species requiring large blocks of unfragmented natural habitat are likely to be disproportionately affected by the development. Reductions in core-habitat area represent a shift in the remaining habitat away from large contiguous habitat blocks toward smaller, more isolated remnants, which may experience edge effects including higher rates of atmospheric deposition, more exotic species, and poorer habitat quality for interior species.

We further examined the suitability of the WHHC parcel for bobcat, fisher, mink, and moose. As of 2006, the WHHC parcel was highly suitable for moose (98 on a 100 scale), bobcat (85), mink (70), and fisher (65). Furthermore, 36 percent of moose highly suitable habitat and 20 percent of bobcat highly suitable habitat across the entire AOI lies within the planned development.

Lastly, we examined potential effects on animal movement between the Schoodic District of ANP in the south to and from other undeveloped lands to the north using a combination of least-cost path analysis and electrical circuit theory. Leastcost path analysis revealed that (as of 2006) the percentage of area of most efficient travel route for moose (62 percent), bobcat (43 percent), fisher (16 percent), and mink (10 percent), lies within the WHHC parcel. Reclassifying the WHHC parcel as developed substantially altered the most efficient travel route for all species. Moose experienced the greatest change in the most efficient travel route (97 percent change), followed by fisher (95 percent change), bobcat (92 percent change), and mink (40 percent change). Furthermore, development of the WHHC parcel resulted in increases in effective resistance (potential barriers to movement) among high-quality patches for bobcat (74 percent), moose (41 percent), fisher (19 percent), and mink ( 5 percent). These results indicate that movement of all four species among high-quality habitat patches and between the ANP and undeveloped lands to the north would be impacted by development of the WHHC parcel, likely resulting in increased energy expenditure by animals in these areas, effects on population density, and a reduction in animal viewings within the ANP boundary. 


\section{Introduction}

Habitat fragmentation (the breaking apart of large contiguous blocks of habitat into smaller, more isolated remnants) is one of the most important factors contributing to species loss worldwide (Wilcox and Murphy, 1985; World Conservation Monitoring Centre, 1992). Fragmentation reduces overall habitat area and habitat suitability, creates more edge per unit area, and modifies the movement of materials, plants, and animals (Kupfer, 2006).

Fragmentation of lands adjacent to national parks can significantly affect park programs, resources, values, and visitor experiences (National Park Service, 2006). For example, newly created edges along fragmented habitat often experience increased atmospheric deposition (Weathers and others, 2001), increased susceptibility to invasive species (Harper and others, 2005), and reduced abundance of shade-tolerant plant species (Foster and others, 1998). Such edge effects may extend for thousands of meters into remaining habitat fragments (Ramaharitra, 2006), with the potential to affect adjacent protected areas.

Most animals move into and out of national parks because park boundaries fail to encompass all regional habitats and species pools. Fragmentation of lands adjacent to national parks could therefore influence animal-movement patterns, leading to increased energy expenditure as organisms search for isolated remnants of suitable habitat. In some cases, fragmentation can completely restrict access to various portions of landscapes, leading to break-up and isolation of populations, and perhaps local extirpation and loss of genetic and species diversity (Zuidema and others, 1996; Lindenmayer and Franklin, 2002). A reduction in animal movement into national parks would reduce wildlife viewing opportunities for park visitors. Conversely, movement of some animals out of national parks could be reduced and lead to overabundant populations. For large herbivores such as moose (Alces alces), reduced movement out of parks could lead to overbrowsing and declines in plant growth, survival, and biodiversity.

As a consequence of the wide-ranging effects of fragmentation of lands adjacent to national parks, the National Park Service (NPS) sought to partner with other organizations and groups to protect park resources and values from unacceptable impacts to adjacent lands (Shands, 1979; Buechner and others, 1992). Central features of management plans that seek to reduce the effects of habitat fragmentation on park resources are corridors that allow for continued movement of organisms across park boundaries (Zube, 1995).

During 2010, the U.S. Geological Survey (USGS) in cooperation with the National Park Service (NPS) conducted a study to examine how the planned development of a 1,295 hectare (ha) parcel adjacent to the Schoodic District of Acadia National Park (ANP), Maine, would impact natural habitat area, habitat suitability, and movement corridors for a variety of species. The Schoodic District of ANP sits at the southern tip of one of the largest contiguous undeveloped habitat blocks remaining on the coast of Maine (Beginning with Habitat, n.d.a). The 890 ha unit of ANP, along with adjacent private lands, includes one of the most outstanding assemblages of jack pine woodlands in Maine. It also hosts several rare plants and provides important habitat for bald eagles, harlequin ducks, wading birds and waterfowl and shorebirds. (Beginning with Habitat, n.d.b). Planned development of a 1,295 ha private block of land (Winter Harbor Holding Company (WHHC)) into a resort could result in a 3.5 kilometer $(\mathrm{km})$ long barrier that cuts across the entire Schoodic Peninsula (fig. 1) and may isolate the Schoodic District of Acadia National Park from undeveloped lands to the north, including the mainland. It has been suggested that the barrier created by development of the WHHC parcel could restrict the movement of species between Park land at the tip of the Peninsula and the mainland north of U.S. Highway 1, ecologically isolating the Park parcel. The Park needs to understand what effect resort development might have on habitat connectivity between the park and other undeveloped lands to the north of U.S. Highway 1.

\section{Approach}

Given the wide array of species and ecological processes affected by fragmentation, it is not feasible to evaluate all the potential effects of development of the WHHC parcel. Therefore, we chose to begin by examining changes to a general cross-habitat measure of natural habitat area (all forest, grassland, shrubland, wetland, and other water bodies subject to natural ecological processes). We further classified natural habitat into core and interior habitat types, which represent relatively unfragmented habitat. Core natural habitat areas are completely surrounded by natural habitat and do not experience edge effects. Interior natural habitat areas are surrounded by greater than 90 percent natural habitat and experience only minor edge effects.

Although edge effects often are examined as fixed-width buffers, some studies indicate that edge effects may extend a variety of distances into patch interiors (Harper and others, 2005; Laurance and others, 2002; Ramaharitra, 2006). Furthermore, effects of fragmentation on animal movement often depend upon the scales across which different species perceive changes to landscape structure. Therefore, we examined the proportion of natural habitat meeting the criterion for core and interior across multiple scales as suggested by Riitters and others $(2000,2002)$. We then applied these methods to locate and quantify changes to each natural habitat type under current conditions and after reclassifying the WHHC parcel as developed. 

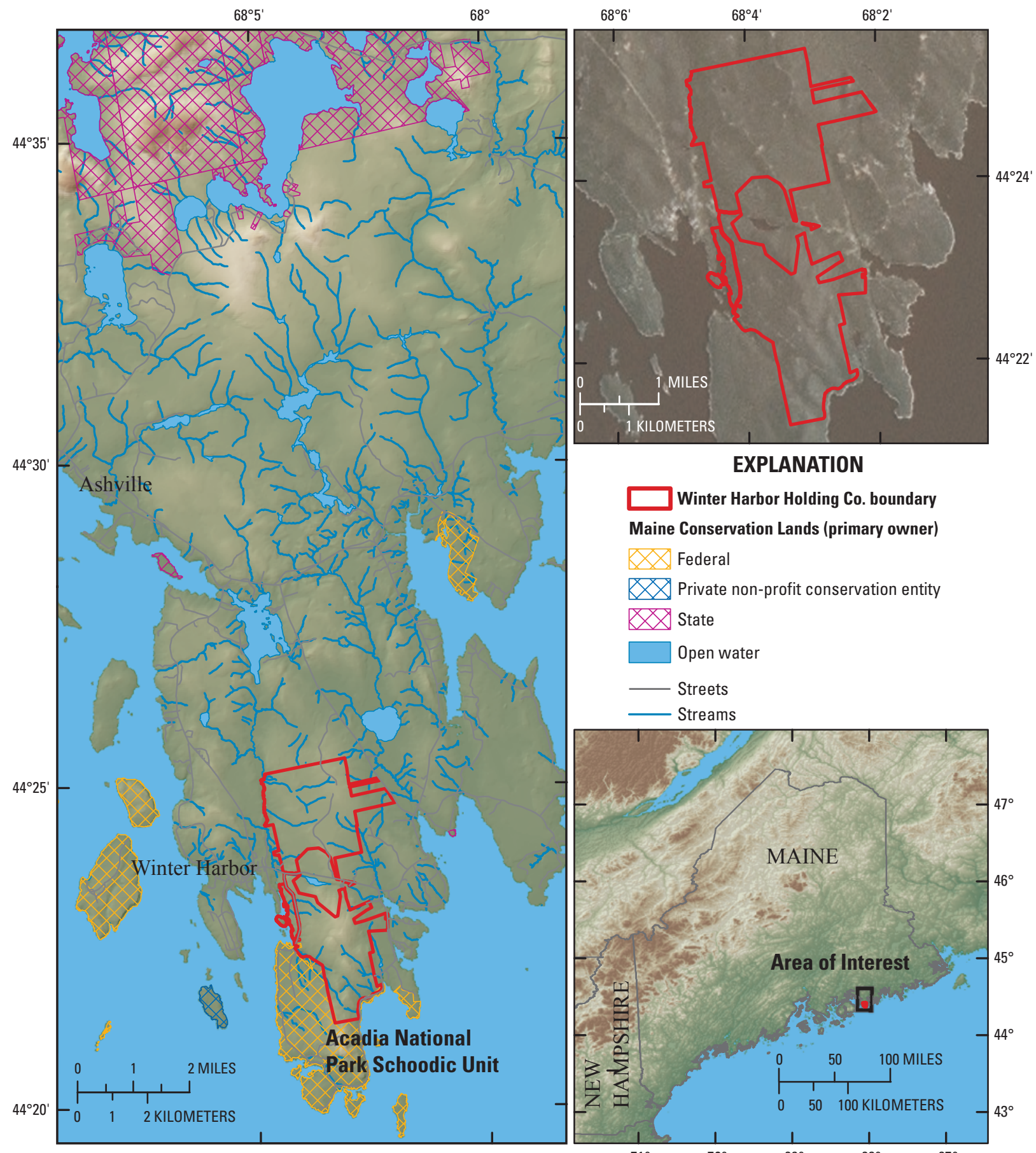

\section{Winter Harbor Holding Co. boundary}

Maine Conservation Lands (primary owner)

$\otimes$ Federal

$\triangle$ Private non-profit conservation entity X State

Open water

Streets

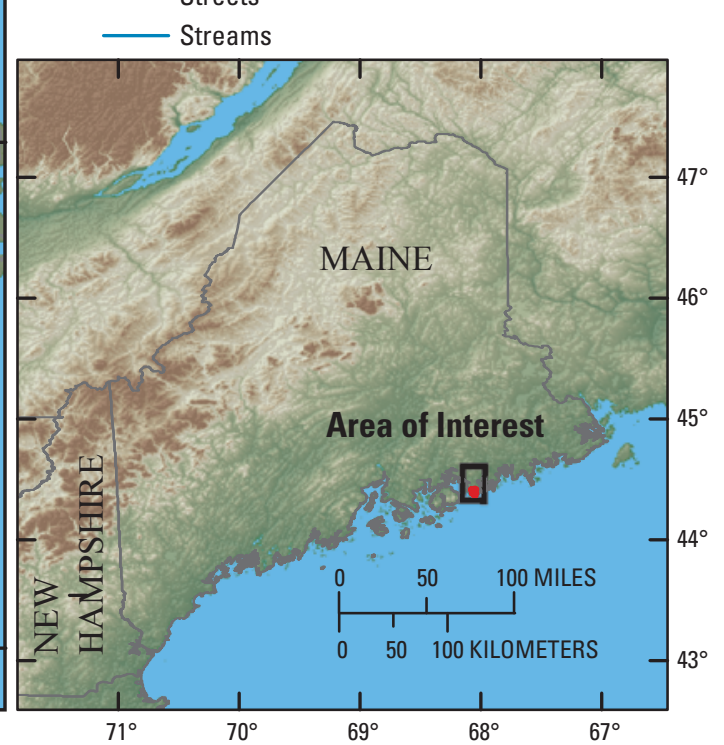

Figure 1. Location of the Schoodic District of Acadia National Park and the Winter Harbor Holding Company parcel. 
Despite the fact that fragmentation affects different species in different ways, we wanted to provide ANP staff with information pertinent to species commonly found in and around the Schoodic Peninsula, which occupy a variety of different types of habitat. We selected bobcat ( $\operatorname{lyn} x$ rufus), a habitat generalist; fisher (Martes pennanti), a species that elects interior portions of large habitat blocks; mink (Neovison vison), a species that elects riparian habitat; and moose (Alces alces), a habitat generalist that favors early successional forests and shrublands. The home ranges of these species vary, but generally are equivalent to the combined size of the ANP unit and the WHHC parcel, which is approximately 20 square kilometers $\left(\mathrm{km}^{2}\right)$. Bobcat home range has been reported at $95.7 \mathrm{~km}^{2}$ for males and $31.2 \mathrm{~km}^{2}$ for females (DeGraaf and Yamasaki, 2001). Fisher home ranges were $30.9 \mathrm{~km}^{2}$ for males and $16.3 \mathrm{~km}^{2}$ average for females (Arthur and others, 1989). Mink home ranges have been reported at an average of $6.5 \mathrm{~km}^{2}$ (Arnold and Fritzell, 1990). Moose home range has been documented as $25 \mathrm{~km}^{2}$ regardless of sex (Leptich and Gilbert, 1989). For each of these species, we used habitat-suitability matrixes to map the distribution of suitable habitat under current conditions and after reclassifying the WHHC parcel as developed. Our results may be extended to other species with similar habitat preferences because we used several species in the analysis.

Lastly, we used two complementary methodologies to model potential changes to landscape connectivity attributable to development of the WHHC parcel. We define landscape connectivity as the degree to which the Schoodic Peninsula and features within the peninsula (the WHHC parcel) facilitate or impede movement of organisms from the ANP boundary to other protected lands to the north. This definition is similar to that provided by (Tischendorf and Fahrig, 2000) but is specific to the Schoodic Peninsula and our interest in identifying potential effects of development of the WHHC parcel on movement of animals into and out of the ANP. The two approaches we used were least-cost path analysis and electrical circuit theory. Both methods estimate some measure of the relative cost, friction, or resistance to organism movement as a function of a species' habitat preference and various landscape features (developments, roads, mountains, and large water bodies).

Least-cost path analysis estimates the cumulative cost or friction that the modeled organism might experience as it moves through the landscape. The cost value in each pixel (picture element) of the map represents the distance to the population source (protected lands to the north of the Schoodic Peninsula), measured as the least effort (lowest cost) in moving over the landscape. The most useful aspect of least-cost path analysis is that it identifies the single most efficient pathway for a given species to move from one point on the landscape to another (from the ANP to protected lands to the north). We are particularly interested in if and how much the most efficient travel routes for our four select species overlap the WHHC parcel. We also are interested in any observed changes in cost associated with animal movement attributable to development of the WHHC parcel.

Electrical circuit theory is similar to least-cost path analysis in that it conceptualizes landscapes as surfaces with relative resistances to movement. Low resistances are assigned to habitats that are most permeable to movement, and high resistances are assigned to poor dispersal habitat or to movement barriers. However, this approach utilizes the theory behind electrical circuit networks. As such, connectivity increases with multiple pathways. As additional pathways are added, individuals do not necessarily travel shorter paths, but have more pathways available to them. Consequently, measures of current density (flow of charge through a cell within the landscape) derived from electrical circuit theory respond positively to increasing the number of pathways in a given circuit network (landscape) (McRae and others, 2008). Areas of exceptionally high current density are commonly referred to as "pinch points" because they have a high likelihood of species movement and removing it would have a large impact on connectivity in the remaining pathways (McRae and others, 2008). For this reason, electrical circuit theory is often used to identify the most important travel routes for various species and hence which habitats should be protected. Whereas the least-cost pathway is the easiest route for a disperser to travel, the current density output identifies the most important routes. We were interested in determining the effects of development on the overall resistance to movement by our four species as well as the change in current density and pinch points owing to development of the WHHC parcel.

Collectively, these methods allowed us to take a comprehensive look at the effects of the proposed development on indicators of cross-habitat fragmentation, species specific habitat suitability, and species specific animal movement. Our goal was to provide ANP staff with information regarding the potential for edge effects within the ANP and across the Schoodic Peninsula as well as the likelihood of animals successfully moving into and out of the ANP parcel.

\section{Methodology}

\section{Study Area}

The area of interest (AOI) for the analyses undertaken was a 14,578 ha area between U.S. Highway 1 to the north and the Schoodic District of ANP to the south. The eastern and western boundaries for the AOI were formed by the Atlantic coastline (fig. 2). This area was selected because the primary importance to ANP staff is the habitat quality and the ability for animals to move between the ANP to the south and the undeveloped lands to the north of U.S. Highway 1. 


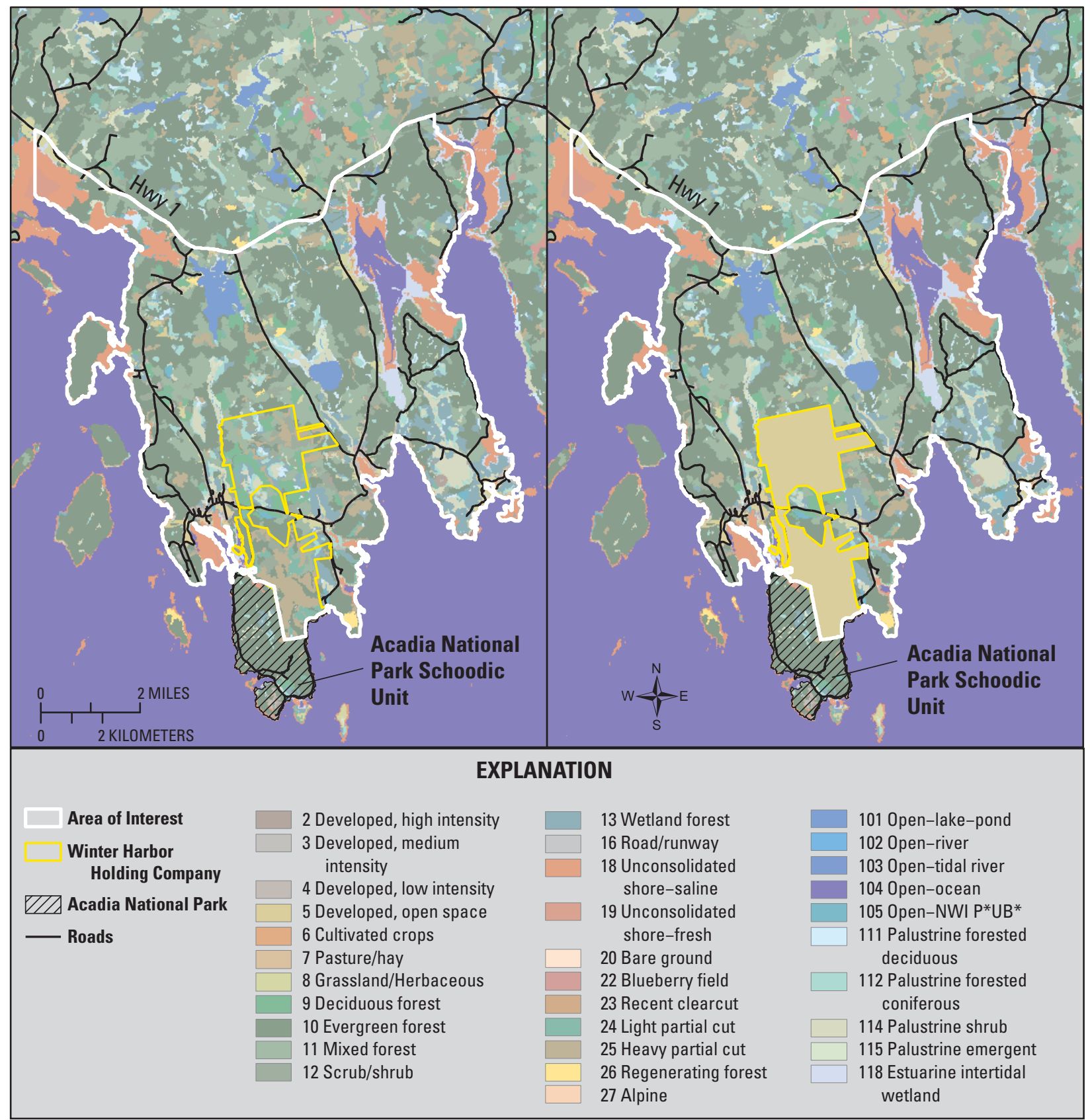

Figure 2. Location of area of interest and Winter Harbor Holding Company (WHHC) parcel overlaid upon current land cover (left) and an alternative land-cover scenario (right) in which the WHHC parcel was reclassified as developed, open space. 
The base land-cover layer used in the analyses was a modified version of the Maine Landcover Dataset (MELCD) - the 5 meter $(\mathrm{m})$ raster land-cover dataset of Maine developed for 2006 by the Maine Office of Geographic Information Systems (MEGIS). Modifications were made to this land-cover layer by the Beginning with Habitat (BWH) connectivity project. The BWH program is a cooperative, non-regulatory effort between State and Federal agencies, conservation groups, and regional governments in Maine. BWH enhanced the wetland and open-water classes using the National Wetlands Inventory (NWI); pixels designated as "road" were removed since linear features do a poor job depicting permeability when represented within a raster dataset. Roads data, received from the Maine Department of Transportation, were utilized at a later stage in some models (typically as a "distance to roads" parameter).
An alternative land-cover layer was developed to represent the WHHC parcel in a future, developed state (fig. 2). To accomplish this, the entire area of the parcel was reattributed as "developed-open space." This type of land cover is typically identified by urban grasses, parks, lawns, and golf courses with a mixture of some constructed materials (Maine Office of Geographic Information Systems, n.d.). This landcover type is the least intense of all of the developed landcover types. Ideally, specific changes to the land cover within the parcel could have been modeled based on specific development plans; however, such information was not made available by the WHHC. We then extracted results for analyses for three different areas (fig. 3): (1) the entire Schoodic Peninsula, our AOI; (2) the area within the WHHC parcel; and (3) highquality habitat patches, which we defined as the top 10 percent of habitat-suitability values (by area) within the entire AOI, based upon a 300-m radius focal mean.
Figure 3. Three separate area of interest (AOI) partitions used to summarize cost-distance and electrical circuit theory model results. The entire Schoodic Peninsula, the AOI, is outlined in white; the area within the Winter Harbor Holding Company parcel is shown in purple; and high-quality habitat patches for the four species are represented as the transparent white overlay.

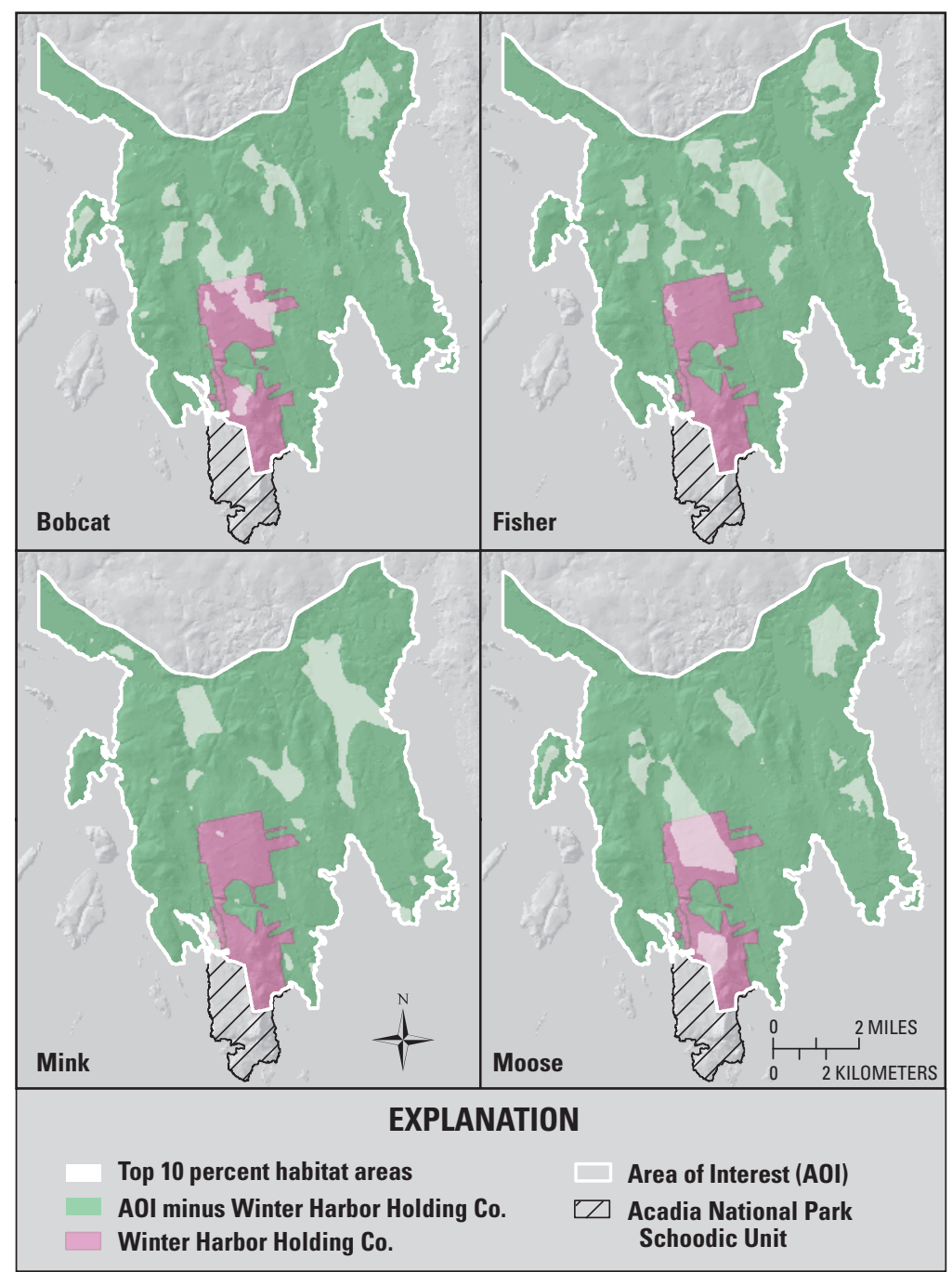




\section{Core and Interior Natural Habitat}

Core and interior natural habitat types were identified for the AOI to be used as a generic indicator of changes to the fragmentation of natural habitat across a range of scales. The AOI for this analysis was the mainland area south of U.S. Highway 1, bounded on the east and west by the Atlantic coastline.

First, all land-cover types were reclassified according to whether they were subject to "natural" ecological processes (succession) (fig. 4). The MELCD was used as the base landcover dataset. For this analysis, a circular window of varying sizes was applied to each natural habitat pixel. These windows are analogous to an organism scanning the area surrounding each natural habitat pixel. Organisms with large home ranges often require larger blocks of natural habitat than species with smaller home ranges; therefore, we used a wide range of window sizes to represent the scale-specific perceptions of different, yet generic species. Furthermore, edge effects on ecosystem properties often extend a variety of distances into patch interiors (Harper and others, 2005; Laurance and others, 2002; Ramaharitra, 2006), yet one cannot predict how far edge effects will extend into a patch. Therefore, we chose to use several window sizes for the analysis $(10,50,100,250,500$, and 1,000 ha) (fig. 4). We used a circular window so that all maximum distances analyzed from the focal cell in any direction were the same distance from the center. We then measured the area density (Pf, proportion of all mapped pixels in the landscape that were natural) within the AOI for each window. Threshold values were set for Pf -1.0 for core natural habitat and (0.9) for interior natural habitat - and then the proportion of natural habitat pixels, for which the surrounding landscape met or exceeded those values, was calculated following Riitters and others $(1997,2000,2002)$. Lastly, the natural habitat pixel in the center of the moving window was designated as "core" if $\mathrm{Pf}=1$, "interior" if $\mathrm{Pf}>0.9$, and simply "natural habitat," if $\mathrm{Pf}<0.9$.

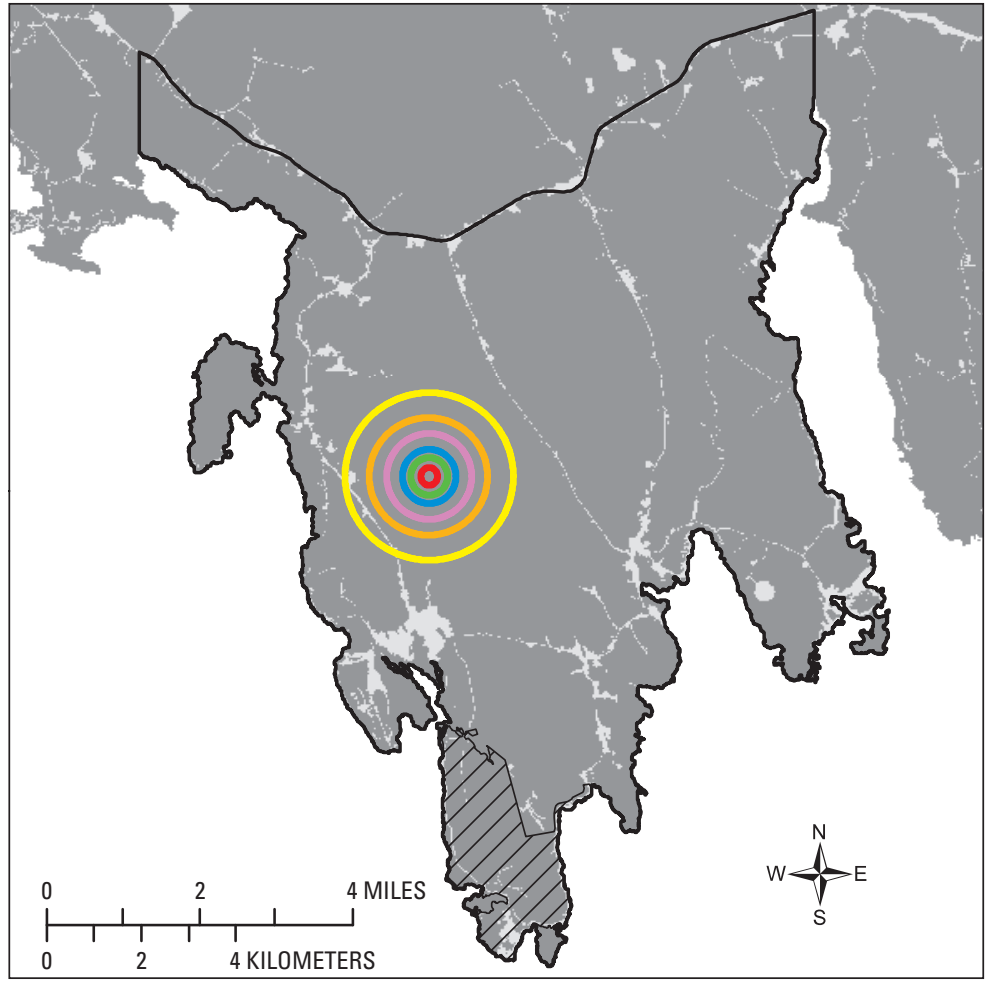

EXPLANATION

\begin{tabular}{clc}
\hline Value & Maine Land Cover Description & Habitat \\
\hline 2 & High intensity developed & 0 \\
3 & Medium intensity developed & 0 \\
4 & Low intensity developed & 0 \\
5 & Open space developed & 0 \\
6 & Cultvated crops & 0 \\
7 & Pasture/hay & 0 \\
8 & Grassland/herbaceous & 1 \\
9 & Deciduous forest & 1 \\
10 & Evergreen forest & 1 \\
11 & Mixed forest & 1 \\
12 & Scrub/shrub & 1 \\
13 & Wetland forest & 1 \\
15 & Wetlands & 1 \\
16 & Roads/runways & 0 \\
19 & Unconsolidated shore & 1 \\
20 & Bare land & 1 \\
21 & Open water & 1 \\
22 & Blueberry field & 1 \\
23 & Recent clearcut & 1 \\
24 & Light partial cut & 1 \\
25 & Heavy partial cut & 1 \\
26 & Regeneratng forest & 1 \\
27 & Alpine & 1 \\
\hline & &
\end{tabular}

Figure 4. Reclassified land-cover map used for core and interior natural habitat analysis ( $1=$ natural habitat (dark grey) and $0=$ non-natural habitat (light grey)). Core natural habitat was identified as areas completely surrounded by natural habitat, and interior natural habitat was surrounded by $>90$ percent natural habitat. Different sized windows were used to evaluate effects of development of the Winter Harbor Holding Company parcel on core and interior natural habitat across a variety of scales. 
Core habitat pixels are surrounded by a completely natural landscape $(\mathrm{Pf}=1.0)$; therefore, they experience no edge effects. Interior habitat has a $\mathrm{Pf} \geq 0.9$; thus, it experiences minor edge effects. By using a variety of window sizes to estimate Pf, the potential for edge effects extending for a wide range of distances can be evaluated.

We quantified the effect development has on the amount of habitat classified as "natural," "core natural," and "interior natural." We then determined how much greater the loss of core and interior natural habitat was as compared to the loss of natural habitat alone (Wickham and others, 2007).

\section{Habitat Suitability}

Our initial goal was to use data generated from a concurrent study using camera traps within the AOI and adjacent areas to quantify the habitat preferences of bobcat (Lynx rufus), fisher (Martes pennanti), mink (Neovison vison), and moose (Alces alces) within our study area (A. Church, Pennsylvania State University, written commun., 2010). However, the objectives of the camera trap study were different from ours and too few camera traps were employed to develop reliable habitat-suitability models for our study. Therefore, we used habitat-suitability models for bobcat, fisher, and mink that were developed for use in the BWH connectivity project (S. Walker, Beginning with Habitat, written commun., 2009). We developed the habitat-suitability model for moose based on our data (De Jager and others, 2009; De Jager and Pastor, 2009) and literature review. Suitability scores within the models we used were based on the relative cost associated with different types of habitat. Scores of 1-3 had low cost and were strongly preferred ( 1 being best); 4 and 5 were usable but suboptimal habitat; 6 and 7 were not breeding habitat, but perhaps occasionally used; and 8-10 had high cost and were strongly avoided (10 being worst) (S. Walker, Beginning with Habitat, written commun., 2009). Another factor influencing habitat suitability was the distance to different road types (based on traffic volume). This companion dataset highlights stretches of roads that, because of their traffic volume, are potential barriers to wildlife movement and may be hotspots for road mortality (Langen and others, 2009). Lastly, mink is a species requiring riparian habitat, and the distance to riparian habitat also was assigned a relative cost value. The final habitat-suitability score for each species was calculated by first converting the cost scores to habitat-suitability scores. Cost is the inverse of suitability, such that the highest cost has the lowest suitability. These costs are translated to suitability scores from 0 to 100 (a cost of 10 translates to a suitability of 0 ; a cost of 1 translates to a suitability of 100). Next, suitability scores for the separate factors (land cover, distance to roads, and distance to riparian habitat) were combined according to the geometric mean using the CorridorDesigner tool "HSM 2-Combine previously reclassified habitat factors" (Majka and others, 2007). This tool creates habitat-suitability models by combining previously reclassified habitat factors using specified weights for each individual factor.

The bobcat habitat-suitability model reflected a preference for forested areas and a strong avoidance of developed areas and roads with high traffic volume (tables 1 and 2). The land-cover component of the model was given a weighting of 75 and distance to roads a weighting of 25 (S. Walker, Beginning with Habitat, written commun., 2009).

The fisher habitat-suitability model was based on land cover alone (table 1), but did include a parameter for habitat patch size, given that fishers prefer interior forest areas. First, the patch sizes of all areas of high habitat score $(\operatorname{cost}=1,2,3)$ were calculated. Then, areas that were $\geq 1,500$ acres remained unchanged, whereas areas that were $<1,500$ acres were multiplied by 0.9 . These sizes were based on one-half of the median female home range size of 1,500 acres. This reduced their suitability but not so much that they dropped below the next suitability level (S. Walker, Beginning with Habitat, written commun., 2009). In this manner, large patches that had scores ranked in the top three classes retained their initial score while smaller blocks of habitat in the top three classes were reduced.

The mink habitat-suitability model was based on land cover, distance to roads, and distance to riparian areas. Within the model, land cover was given a weighting of 65 , distance to riparian areas a weighting of 25 , and distance to roads a weighting of 10. All wetland types adjacent to or intersected by rivers, perennial streams, lakes, ponds, or the ocean were ranked a cost of 1 ; all others were ranked a cost of 4 . Isolated wetlands (NWI classification PUB) were ranked 1 if they were part of a stream or river system and 4 if they were isolated. Open waters over $500 \mathrm{~m}$ from shore/banks of riparian areas were excluded as unsuitable habitat (S. Walker, Beginning with Habitat, written commun., 2009). Tables 1 and 2 show the costs associated with land cover and roads for mink. Costs associated with riparian areas were as follows: $0-30 \mathrm{~m}=1,30-300 \mathrm{~m}=5$, and $>300 \mathrm{~m}=10$.

The moose habitat-suitability model was based on land cover and distance to roads (tables 1 and 2). Within the model, land cover was given a weighting of 85 and distance to roads a weighting of 15 . Land-cover cost scores were modified based upon their proximity to riparian habitat. Pasture/hay and grassland/herbaceous land-cover types were given a cost value of 2 if they were within $100 \mathrm{~m}$ of riparian habitat; otherwise, they were given a cost value of 6 .

The habitat-suitability scores were mapped for each species according to the current land-cover scenario, distance to roads, and riparian habitat as well as for an alternative scenario in which the WHHC parcel was reclassified as developed (fig. 2). We calculated the mean habitat-suitability scores for (1) the entire AOI, (2) the WHHC parcel, and (3) the highestquality habitat patches (top 10 percent of habitat-suitability scores). 
Table 1. Habitat-suitability scores, based on land cover, for bobcat, fisher, mink, and moose.

[Scores of 1-3 were low cost and strongly preferred ( 1 being best); 4 and 5 were usable but suboptimal habitat; 6 and 7 were not breeding habitat, but occasionally used; and 8-10 were high cost and strongly avoided (with 10 being worst) (Walker and others, 2009)]

\begin{tabular}{|c|c|c|c|c|}
\hline \multirow{2}{*}{ Land-cover class } & \multicolumn{4}{|c|}{ Cost } \\
\hline & Bobcat & Fisher & Mink & Moose \\
\hline High-intensity development & 10 & 10 & 10 & 10 \\
\hline Medium-intensity development & 6 & 9 & 7 & 9 \\
\hline Low-intensity development & 5 & 8 & 6 & 8 \\
\hline Developed open space & 9 & 7 & 7 & 7 \\
\hline Cultivated crops & 4 & 8 & 6 & 6 \\
\hline Pasture/hay & 4 & 8 & 6 & 6 \\
\hline Grassland/herbaceous & 4 & 8 & 6 & 6 \\
\hline Deciduous forest & 2 & 1 & 4 & 1 \\
\hline Evergreen forest & 2 & 1 & 4 & 1 \\
\hline Mixed forest & 2 & 1 & 4 & 1 \\
\hline Scrub/shrub & 1 & 3 & 1 & 1 \\
\hline Wetland forest & 3 & 5 & 1 & 1 \\
\hline Runway & 10 & 9 & 10 & 10 \\
\hline Unconsolidated shore - saline & 8 & 10 & 4 & 6 \\
\hline Unconsolidated shore - fresh & 8 & 10 & 4 & 6 \\
\hline Bare ground & 9 & 10 & 8 & 10 \\
\hline Blueberry field & 4 & 10 & 6 & 6 \\
\hline Recent clear-cut & 3 & 10 & 6 & 1 \\
\hline Light partial cut & 3 & 8 & 3 & 1 \\
\hline Heavy partial cut & 3 & 8 & 5 & 1 \\
\hline Regenerating forest & 3 & 1 & 4 & 1 \\
\hline Alpine & 6 & 5 & 9 & 4 \\
\hline Open lake-pond & 10 & 10 & 1 & 4 \\
\hline Open - river & 10 & 10 & 1 & 7 \\
\hline Open - tidal river & 10 & 10 & 1 & 7 \\
\hline Open - ocean & 10 & 10 & 1 & 10 \\
\hline Open_NWI P*UB* & 10 & 10 & 1 & 10 \\
\hline Palustrine forested coniferous & 3 & 5 & 1 & 1 \\
\hline Palustrine forested deciduous & 3 & 5 & 1 & 1 \\
\hline Palustrine shrub wetland & 2 & 3 & 1 & 1 \\
\hline Palustrine emergent wetland & 5 & 10 & 1 & 2 \\
\hline Estuarine emergent wetland & 5 & 10 & 1 & 2 \\
\hline
\end{tabular}


Table 2. Costs associated with distance to roads with varying traffic volumes.

[N/A, not applicable; >, greater than; scores of 1-3 were low cost and strongly preferred (1 being best); 4 and 5 were usable but suboptimal habitat; 6 and 7 were not breeding habitat, but occasionally used; and 8-10 were high cost and strongly avoided (with 10 being worst) (Walker and others, 2009)]

\begin{tabular}{|c|c|c|c|c|c|}
\hline \multirow{2}{*}{$\begin{array}{l}\text { Average daily } \\
\text { traffic volume }\end{array}$} & \multirow{2}{*}{$\begin{array}{l}\text { Distance from road } \\
\text { (meters) }\end{array}$} & \multicolumn{4}{|c|}{ Cost } \\
\hline & & Bobcat & Fisher & Mink & Moose \\
\hline \multirow[b]{4}{*}{ 0-99 } & $0-100$ & 2 & N/A & 1 & 2 \\
\hline & $100-500$ & 1 & N/A & 1 & 1 \\
\hline & $500-1,000$ & 1 & N/A & 1 & 1 \\
\hline & $>1,000$ & 1 & N/A & 1 & 1 \\
\hline \multirow[b]{4}{*}{$100-499$} & $0-100$ & 3 & N/A & 2 & 3 \\
\hline & $100-500$ & 1 & N/A & 2 & 1 \\
\hline & $500-1,000$ & 1 & N/A & 1 & 1 \\
\hline & $>1,000$ & 1 & N/A & 1 & 1 \\
\hline \multirow[b]{4}{*}{$500-2,999$} & $0-100$ & 6 & N/A & 4 & 6 \\
\hline & $100-500$ & 2 & N/A & 3 & 2 \\
\hline & $500-1,000$ & 2 & N/A & 1 & 2 \\
\hline & $>1,000$ & 1 & N/A & 1 & 1 \\
\hline \multirow[b]{4}{*}{$3,000-5,999$} & $0-100$ & 7 & N/A & 7 & 7 \\
\hline & $100-500$ & 4 & N/A & 5 & 4 \\
\hline & $500-1,000$ & 2 & N/A & 3 & 2 \\
\hline & $>1,000$ & 1 & N/A & 1 & 1 \\
\hline \multirow{7}{*}{$6,000-9,999$} & $0-100$ & 8 & N/A & 9 & 8 \\
\hline & $100-500$ & 4 & N/A & 5 & 4 \\
\hline & $500-1,000$ & 3 & N/A & 3 & 3 \\
\hline & $>1,000$ & 1 & N/A & 1 & 1 \\
\hline & $0-100$ & 9 & N/A & 10 & 9 \\
\hline & $100-500$ & 5 & N/A & 5 & 5 \\
\hline & $500-1,000$ & 2 & N/A & 3 & 2 \\
\hline$>10,000$ & $>1,000$ & 1 & N/A & 1 & 1 \\
\hline
\end{tabular}




\section{Least-Cost Corridor}

Traditionally, habitat connectivity has been calculated using least-cost connectivity modeling (Walker and Craighead, 1997). The least-cost algorithm is applied as follows: for any given movement from cell $\mathrm{N}_{\mathrm{i}}$ to cell $\mathrm{N}_{\mathrm{i}+1}$, the cumulative cost is calculated as the cost to reach cell $\mathrm{N}_{\mathrm{i}}$ plus the average cost to move through cell $\mathrm{N}_{\mathrm{i}}$ and $\mathrm{N}_{\mathrm{i}+1}$. The model is based on an eight-neighbor cell algorithm, which allows for movements along the diagonals. For diagonal movements, the cost is multiplied by the square root of 2 to compensate for the longer distance.

The least-cost path is identified as the path of least cumulative cost from one point on a map to another point (source nodes) (fig. 5), given the cost associated with movement through various habitat types. For this study, we estimated movement between high-quality habitat-suitability areas in the Schoodic District of ANP to high-quality habitat-suitability areas north of U.S. Highway 1. High-quality habitat-suitability areas were defined as those areas that had a habitat-suitability score of $\geq 90$. We used these as starting points for animal movement since these would be the most likely sources for species of interest to travel to and from. For the cost associated with movement of each species through each type of habitat, we applied the cost scores used to develop the habitat suitability models. Suitability scores of 1-3 were assigned to highly preferred habitat, which had low cost ( 1 being best); 4 and 5 were usable but suboptimal habitat and had associated intermediate cost; 6 and 7 were not breeding habitat, but perhaps occasionally used; and 8-10 had high cost and were strongly avoided (10 being worst) (S. Walker, Beginning with Habitat, written commun., 2009). Given the sources of movement and the intervening land cover and associated habitat suitability, a cost-distance surface is produced (fig. 6), which displays cumulative cost associated with moving across the landscape. We examined changes to the mean cost distance across the AOI, within the WHHC parcel, and within the highest-quality habitat patches within the AOI for each species before and after development of the WHHC parcel. We also identified the most efficient travel corridor as the lowest 10 percent of cost-distance values and examined how much of this corridor overlapped with the WHHC parcel. Cost distance and the least-cost path were calculated for each scenario and species using the "Create corridor model" tool from the CorridorDesigner Toolbox (Majka and others, 2007).

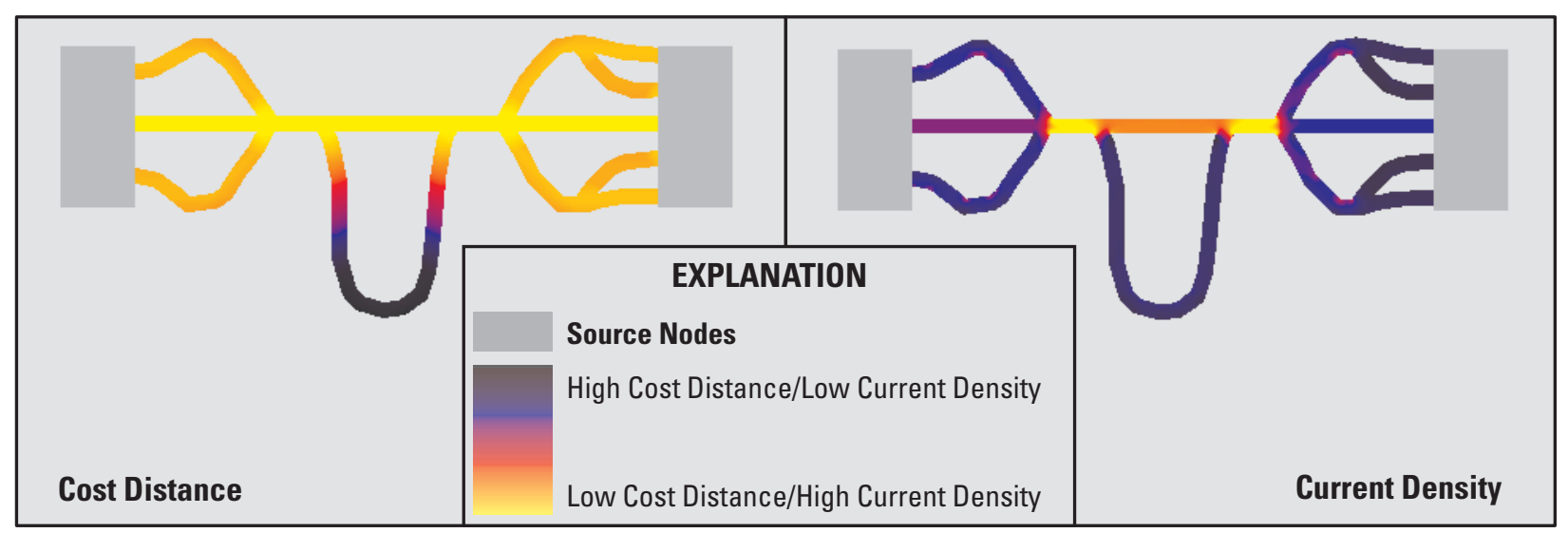

Figure 5. Differences in how cost-distance and electrical circuit theory methods calculate habitat connectivity using a hypothetical landscape (adapted from McRae and others 2008). The cost-distance algorithm identifies a single, besttravel corridor, whereas the current density algorithm allows the user to identify and quantify the current flowing through alternative pathways and to further identify corridors or pinch points of high current density. 


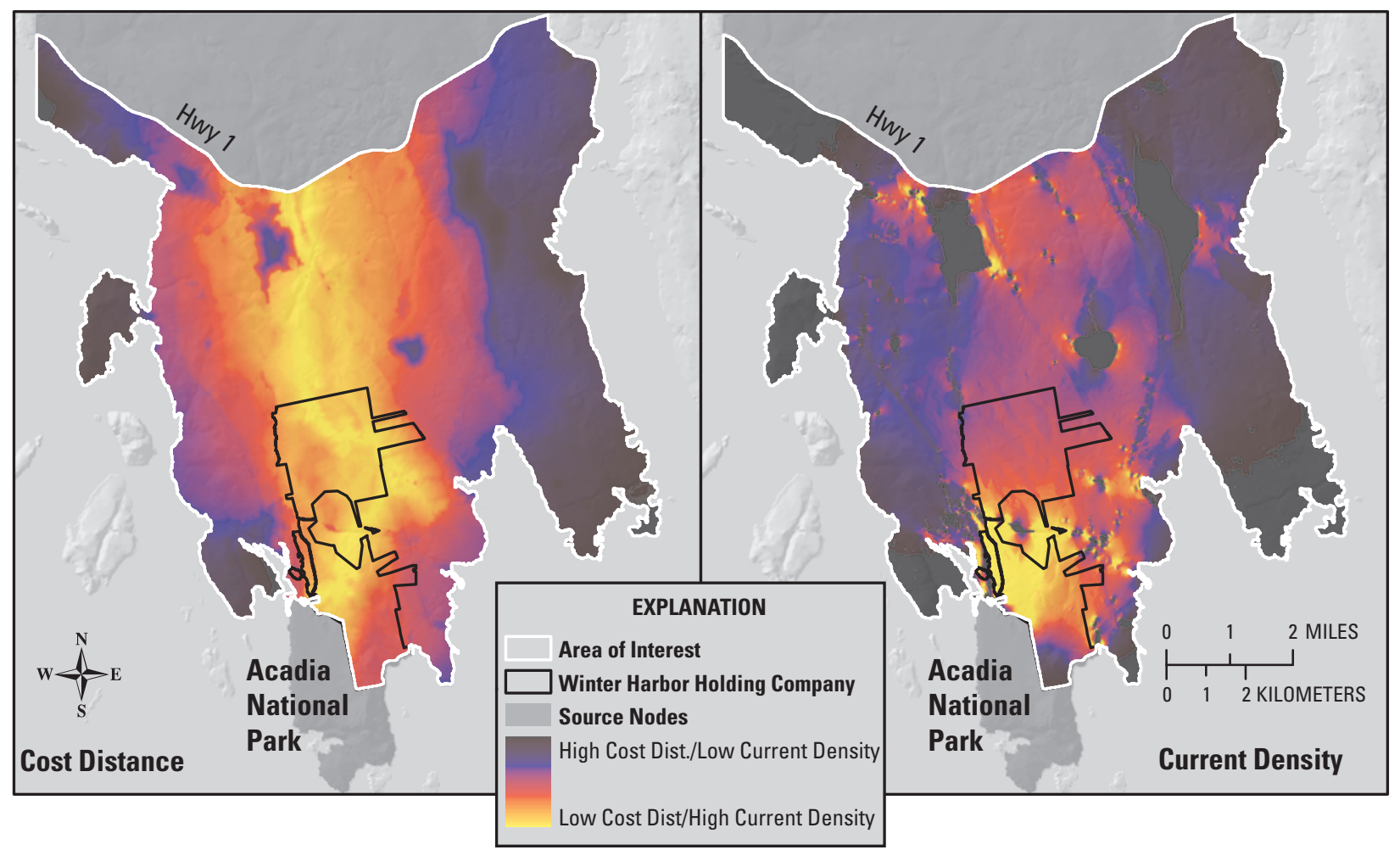

Figure 6. Differences in how cost-distance and electrical circuit theory methods calculate habitat connectivity using an actual landscape. The cost-distance algorithm identifies a single, best-travel corridor, whereas the current density algorithm allows the user to identify and quantify the current flowing through alternative pathways and to further identify corridors or pinch points of high current density.

\section{Electrical Circuit Theory}

The primary limitation of least-cost corridor analysis is that only a single movement path is identified, even though alternative paths with comparable costs might exist (Pinto and Keitt, 2008). In contrast, electrical circuit theory can be used to identify several of the most important travel routes between two locations (McRae, 2006; McRae and Beier, 2007). Distance metrics based on electrical connectivity increase with the number of connections because connectivity increases with multiple pathways in circuit networks (McRae and others, 2008). As additional pathways are added, individuals do not necessarily travel shorter paths, but have more pathways available to them.

As with least-cost analysis, electrical circuit theory begins with a landscape of costs based on habitat suitability. The area is represented as conductive surfaces, with low resistances assigned to habitats that are most permeable to movement and high resistances assigned to poor dispersal habitat or to movement barriers, instead of estimating cumulative costs. One measure that can be derived from these maps is the effective resistance, the calculated resistance to current flow between two specified nodes. This measurement provides a single measure of the relative difficulty with which a species can move from one node to another. We calculated effective resistance using Circuitscape 3.5.1 (McRae and Shah, 2009) before and after development of the WHHC parcel as a measure of the likely effects of fragmentation on ease of animal movement between high-quality habitat-suitability areas within the ANP boundary and high-quality habitat-suitability areas north of U.S. Highway 1.

Another useful measure of the ease of animal movement is current density, the equivalent of the flow of charge through a cell within the landscape (figs. 5 and 6). Current density can be used to estimate the expected net number of times that a random walker, starting at one node and walking until it reaches another node, will move along a particular portion of the landscape. Markovian random walk theory was used since this constrains the current to relatively efficient routes and keeps it from going through far-flung portions of the landscape that are too costly to result in a successful dispersal. We estimated mean current densities for the AOI, the WHHC parcel, and high-quality habitat patches before and after development of the WHHC parcel for each species.

Lastly, we identified pinch points of exceptionally high current density. Such areas highlight portions of the landscape that have a high likelihood of species movement. High current through a pathway indicates that removing or converting it will have a high impact on connectivity in the remaining pathways (McRae and others, 2008). 
For both the least-cost corridor analysis and electrical circuit theory analysis, we modeled animal movement between high-quality habitat suitability areas within the Schoodic District of ANP in the south and high-quality habitat suitability areas within the polygonal area north of U.S. Highway 1. It is important to note that when Circuitscape calculates the current flow from one node to another, it will always choose to travel through the node as long as possible rather than venturing out into the matrix between the nodes. This becomes evident in figure 6, where current density is highest at the north end of the Schoodic District of ANP.

\section{Results and Discussion}

\section{Core and Interior Natural Habitat}

As of 2006, approximately 95 percent of the entire 14,578 ha AOI was considered natural habitat. Comparatively, the WHHC parcel consists of 99 percent natural habitat. Reclassifying the WHHC parcel as developed reduced the amount of natural habitat across the entire AOI by 9.6 percent.
However, the estimated loss of core natural habitat (100 percent unfragmented) attributable to development of the WHHC parcel ranged from 16 to 84 percent, depending upon the size of the analysis window (scale of the analysis) (table 3 ). The percentage loss of core natural habitat ranged from 1.6 to 8.7 times greater than the percentage loss of natural habitat. Similar results were found for interior natural habitat ( $>90$ percent unfragmented). The estimated loss of interior natural habitat owing to development of the WHHC parcel ranged from 13 to 29 percent, depending upon the scale of our analysis, and this loss was 1.4 to 3.1 times greater than the percentage loss of fragmented natural habitat (table 3 ). These results represent a shift in the remaining natural habitat from core (completely unfragmented) and interior (only slightly fragmented) to fragmented natural habitat. Loss of core and interior natural habitat was greatest at the largest scales of analysis, indicating that species with larger home ranges, which require larger blocks of contiguous habitat, are likely to be affected by the development of the WHHC parcel disproportionately more so than organisms with smaller home ranges, which require smaller blocks of natural habitat (figs. 7 and 8 ).

Table 3. The change in core (unfragmented) and interior (slightly fragmented) natural habitat area within the area of interest owing to development of the Winter Harbor Holding Company parcel.

[Percentage loss is relative to the amount of each habitat type under current conditions. The ratio is the percentage loss of each habitat type divided by the overall percentage loss of natural habitat owing to development, which was 9.6 percent]

\begin{tabular}{|c|c|c|c|c|c|}
\hline Scale & $\begin{array}{c}\text { Core } \\
\text { natural habitat, } \\
\text { current conditions } \\
\text { (hectares) }\end{array}$ & $\begin{array}{c}\text { Core } \\
\text { natural habitat, } \\
\text { developed } \\
\text { (hectares) }\end{array}$ & Difference & $\begin{array}{c}\text { Percentage } \\
\text { loss }\end{array}$ & Ratio \\
\hline 10 & $9,380.49$ & $7,901.95$ & $1,478.54$ & 15.762 & 1.64 \\
\hline 50 & $6,457.22$ & $5,066.46$ & $1,390.76$ & 21.538 & 2.24 \\
\hline 100 & $4,689.77$ & $3,518.85$ & $1,170.91$ & 24.967 & 2.60 \\
\hline 250 & $2,698.41$ & $1,882.65$ & 815.76 & 30.231 & 3.15 \\
\hline 500 & $1,343.01$ & 791.40 & 551.61 & 41.073 & 4.28 \\
\hline 1,000 & 339.63 & 54.78 & 284.85 & 83.872 & 8.74 \\
\hline Scale & $\begin{array}{c}\text { Interior } \\
\text { natural habitat, } \\
\text { current conditions } \\
\text { (hectares) }\end{array}$ & $\begin{array}{c}\text { Interior } \\
\text { natural habitat, } \\
\text { developed } \\
\text { (hectares) }\end{array}$ & Difference & $\begin{array}{c}\text { Percentage } \\
\text { loss }\end{array}$ & Ratio \\
\hline 10 & $12,192.56$ & $10,577.99$ & $1,614.57$ & 13.242 & 1.38 \\
\hline 50 & $11,843.29$ & $9,950.37$ & $1,892.92$ & 15.983 & 1.66 \\
\hline 100 & $11,782.19$ & $9,694.62$ & $2,087.57$ & 17.718 & 1.85 \\
\hline 250 & $12,221.15$ & $9,688.45$ & $2,532.71$ & 20.724 & 2.16 \\
\hline 500 & $12,361.73$ & $9,269.51$ & $3,092.21$ & 25.014 & 2.61 \\
\hline 1,000 & $12,299.04$ & $8,676.36$ & $3,622.68$ & 29.455 & 3.07 \\
\hline
\end{tabular}




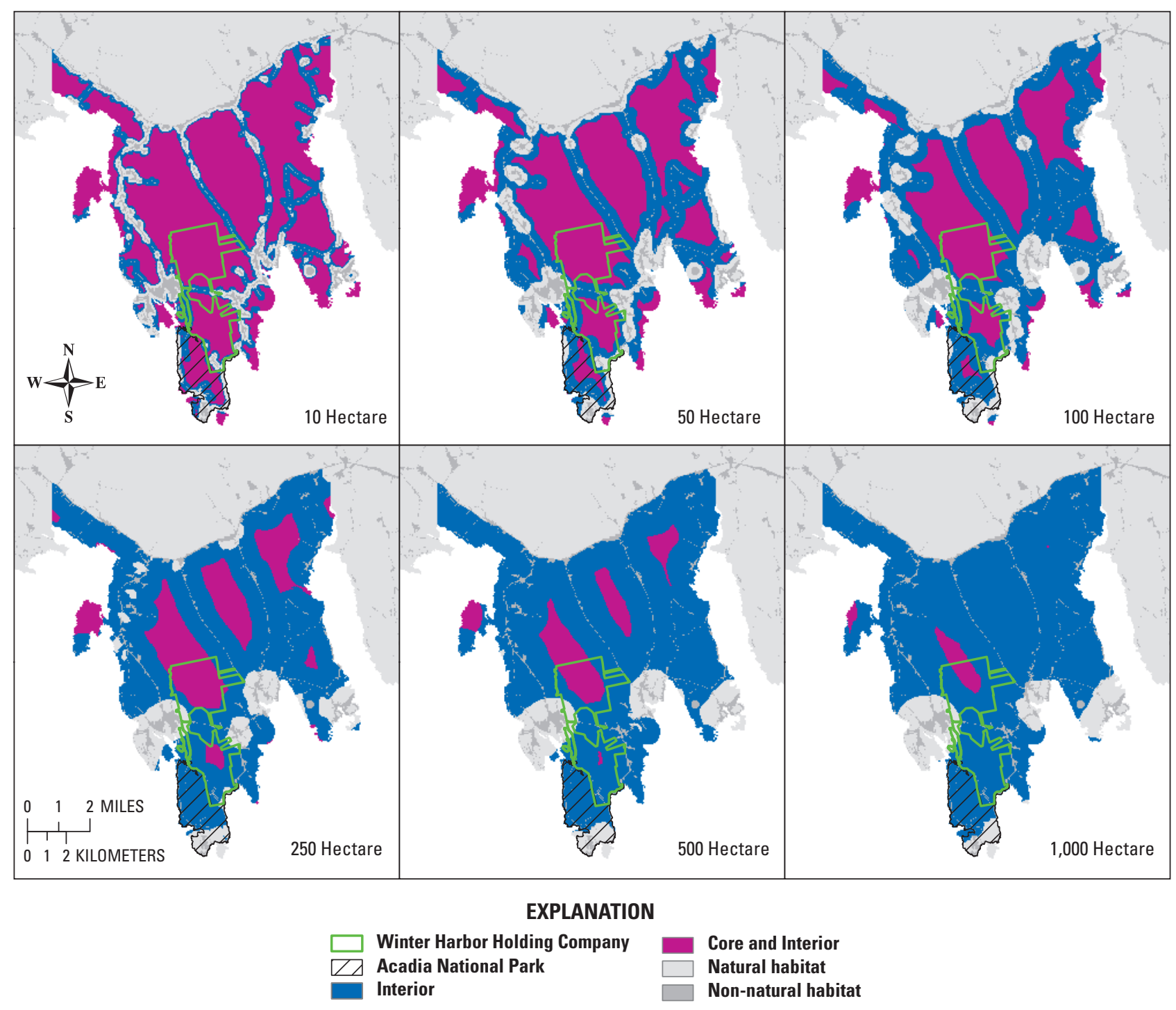

Figure 7. Distribution of core (100 percent natural) and interior (>90 percent natural) habitat under the current, undeveloped conditions for the Schoodic Peninsula. Note the decline in core habitat with increasing window size, but the maintenance of interior habitat. 


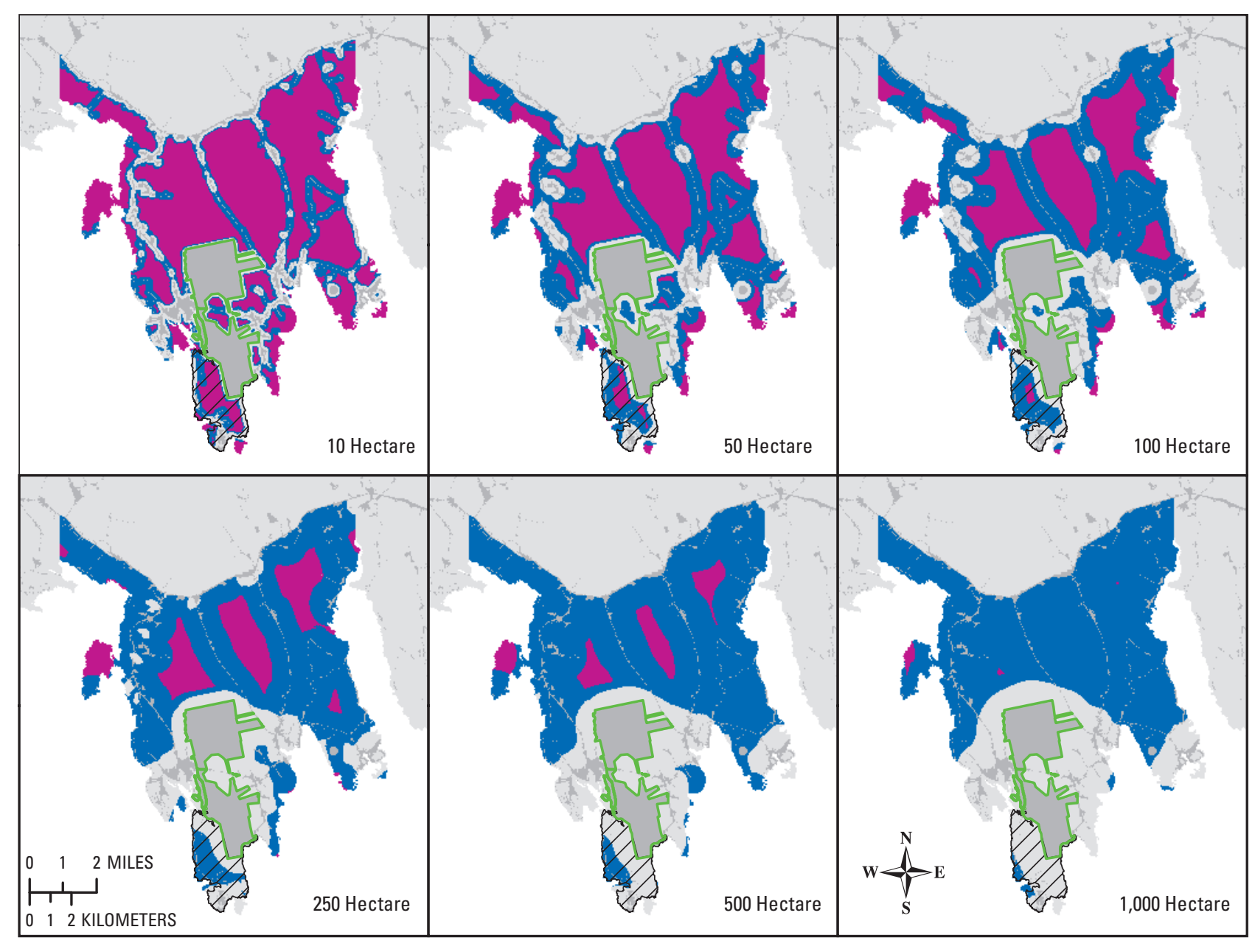

\section{EXPLANATION}

Winter Harbor Holding Company Acadia National Park Interior

Core and Interior

Natural Habitat

Non-natural Habitat

Figure 8. Distribution of core (100 percent natural) and interior ( $>90$ percent natural) habitat after reclassifying the Winter Harbor Holding Company parcel as developed. Note the decline in both core and interior habitat with increasing window size. 
Although development of the WHHC parcel would result in no change in the total amount of natural habitat within the boundary of the Schoodic District of ANP, development would impact ANP habitat through increased edge effects. Without development, over 68 percent of the natural habitat within the ANP boundary met the criterion of interior habitat ( $>90$ percent unfragmented), regardless of the window size used for analysis. However, reclassifying the WHHC parcel to developed reduced interior habitat found within the ANP at each window size (figs. 7-9). The greatest loss of interior habitat occurred at the largest window size (approximately 90-percent reduction). Core natural habitat loss attributable to development of the WHHC parcel was much less than that observed for interior habitat. This was mostly owing to the lack of core habitat under existing conditions. The changes to interior natural habitat within the ANP boundary represent an increase in the edge effects experienced by ANP habitat as a result of development adjacent to the ANP.

The introduction of edge owing to habitat fragmentation can lead to changes in ecosystem structure, composition, and function (Laurance and others, 2002; Harper and others, 2005). For example, habitat edges receive higher rates of atmospheric deposition (Weathers and others, 2001), a higher probability of invasion by exotic species (Harper and others, 2005), and host fewer shade tolerant plant species (Foster and others, 1998). However, it is difficult to determine how far edge effects will extend into patch interiors. Harper and others (2005) reported edge effects including seedling and tree mortality as well as exotic species invasion and changes to community composition that extended $100 \mathrm{~m}$ into forest patch interiors. Laurance and others (2002) reported increased wind disturbance, tree mortality, and insect invasion as far as $400 \mathrm{~m}$ into patch interiors. Lastly, Ramaharitra (2006) reported a maximum edge effect distance of 2,000 m. Comparatively, our 100 ha analysis window had a radius of $1,784 \mathrm{~m}$. According to our analysis, if edge effects extend 2,000 $\mathrm{m}$ beyond the WHHC parcel and into ANP, fewer than 10 percent of park habitat would meet the criterion for "interior natural habitat" compared with over 70 percent of the habitat meeting this criterion if the WHHC parcel is not developed. The changes to interior natural habitat within the ANP boundary represent an increase in habitat experiencing edge effects owing to the development of adjacent lands.

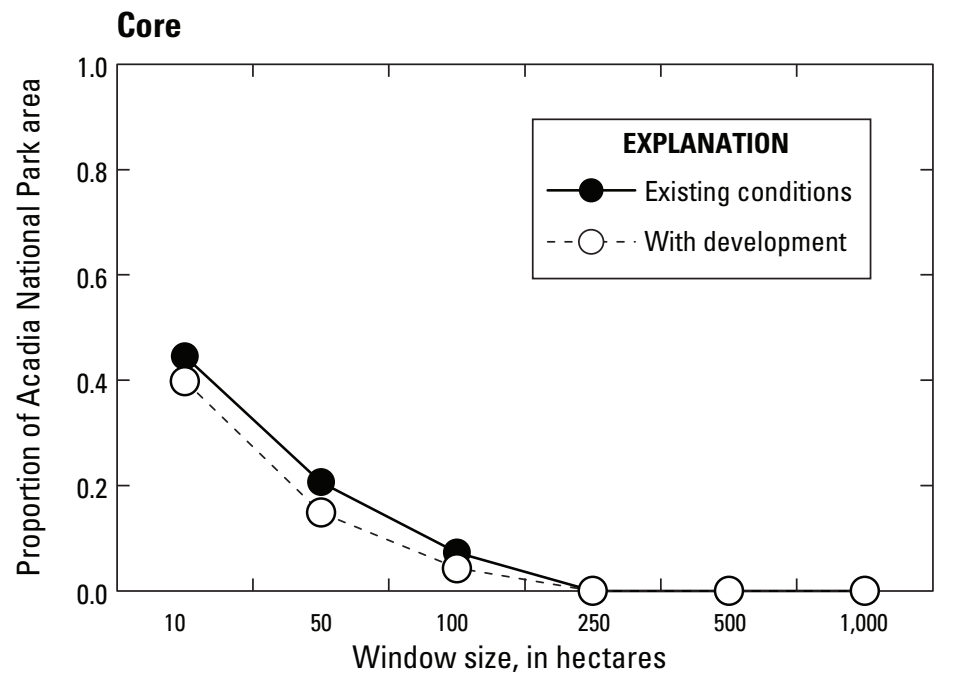

Figure 9. Change in the proportion of natural habitat within the Schoodic District of Acadia National Park meeting the criteria of core (100 percent natural) and interior ( $>90$ percent natural) habitat. Note the decline in interior habitat with increasing scale attributable to development of the Winter Harbor Holding Company parcel.

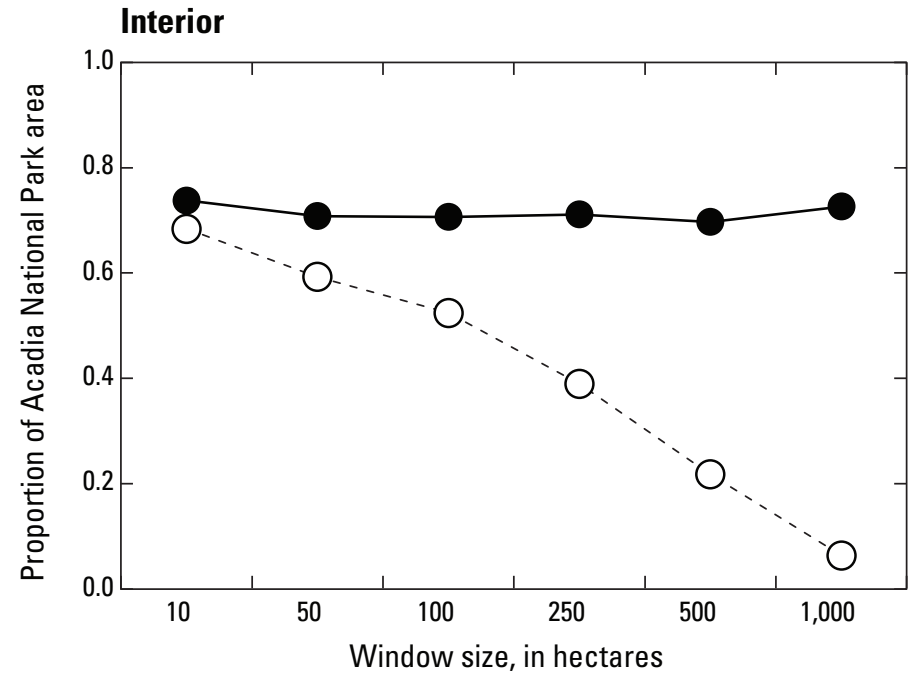




\section{Habitat Suitability}

As of 2006, (without development of the WHHC parcel), the entire Schoodic Peninsula was highly suitable for moose (86.46 percent), bobcat ( 74.32 percent), mink (72.66 percent), and fisher (64.66 percent) (table 4). Habitat suitability across the entire AOI was slightly lower than for the WHHC parcel, which had the highest habitat suitability for each species except mink and fisher. Habitat suitability also was generally high within the ANP boundary: bobcat (81.27 percent), fisher (75.75 percent), moose ( 91.52 percent), and mink (65.35 percent). Under current conditions, both the WHHC and ANP parcels represent very high-quality habitat for these four species based upon the land-cover map provided by BWH.

Table 4. Habitat-suitability model mean values, by area of interest partitions.

\begin{tabular}{|c|c|c|c|c|}
\hline $\begin{array}{l}\text { Area of } \\
\text { interest } \\
\text { partition }\end{array}$ & Species & $\begin{array}{c}\text { Without } \\
\text { development }\end{array}$ & $\begin{array}{c}\text { With } \\
\text { development }\end{array}$ & $\begin{array}{c}\text { Percent } \\
\text { difference }\end{array}$ \\
\hline \multirow{4}{*}{$\begin{array}{l}\text { Entire area } \\
\text { of interest }\end{array}$} & Bobcat & 74.32 & 67.59 & -9.05 \\
\hline & Fisher & 64.66 & 61.5 & -4.89 \\
\hline & Mink & 72.66 & 71.6 & -1.45 \\
\hline & Moose & 86.46 & 80.54 & -6.85 \\
\hline \multirow{4}{*}{$\begin{array}{l}\text { Winter } \\
\text { Harbor } \\
\text { Holding } \\
\text { Company } \\
\text { parcel }\end{array}$} & Bobcat & 86.44 & 19.07 & -77.94 \\
\hline & Fisher & 63.63 & 33.13 & -47.94 \\
\hline & Mink & 70.12 & 42.93 & -38.78 \\
\hline & Moose & 98.53 & 38.07 & -61.36 \\
\hline \multirow{4}{*}{$\begin{array}{l}\text { High-quality } \\
\text { habitat } \\
\text { patches }\end{array}$} & Bobcat & 91.01 & 76.53 & -15.91 \\
\hline & Fisher & 98.81 & 97.54 & -1.29 \\
\hline & Mink & 90.55 & 90.24 & -.35 \\
\hline & Moose & 99.97 & 77.95 & -22.03 \\
\hline
\end{tabular}

Reclassifying the WHHC parcel as developed predictably had the largest impact on habitat-suitability scores within the WHHC parcel (table 4). Declines in habitat suitability within the WHHC parcel ranged from 39 to 78 percent, depending upon species. The suitability of high-quality habitat patches was reduced by 16 percent for bobcat and 22 percent for moose within the AOI; this was mainly owing to the overlap of high-quality patches for these species with the WHHC parcel (figs. 10-13). For moose in particular, the land within the WHHC parcel represents near perfect habitat, much of it being early successional forest. The loss of this habitat owing to development of the WHHC parcel is forecasted to reduce habitat suitability for moose. For fisher, there were areas within the WHHC parcel that exhibited an increase in habitat-suitability scores with development. This is owing to the conversion of areas originally classified as "light partial cut" or "heavy partial cut," which were given cost of 8 in the model, to "developed, open space," which was given a cost of 7 in the BWH models.

Unlike the multi-scale analysis for interior and core habitat, the modeling framework for habitat suitability assumes no adverse effects on adjacent lands. As such, mean habitat-suitability scores within the ANP boundary and across the entire peninsula were relatively unchanged following development of the WHHC parcel. However, reductions in the suitability of habitat within the WHHC parcel are likely to alter the cost associated with animal movement between the ANP and lands to the north of U.S. Highway 1. 


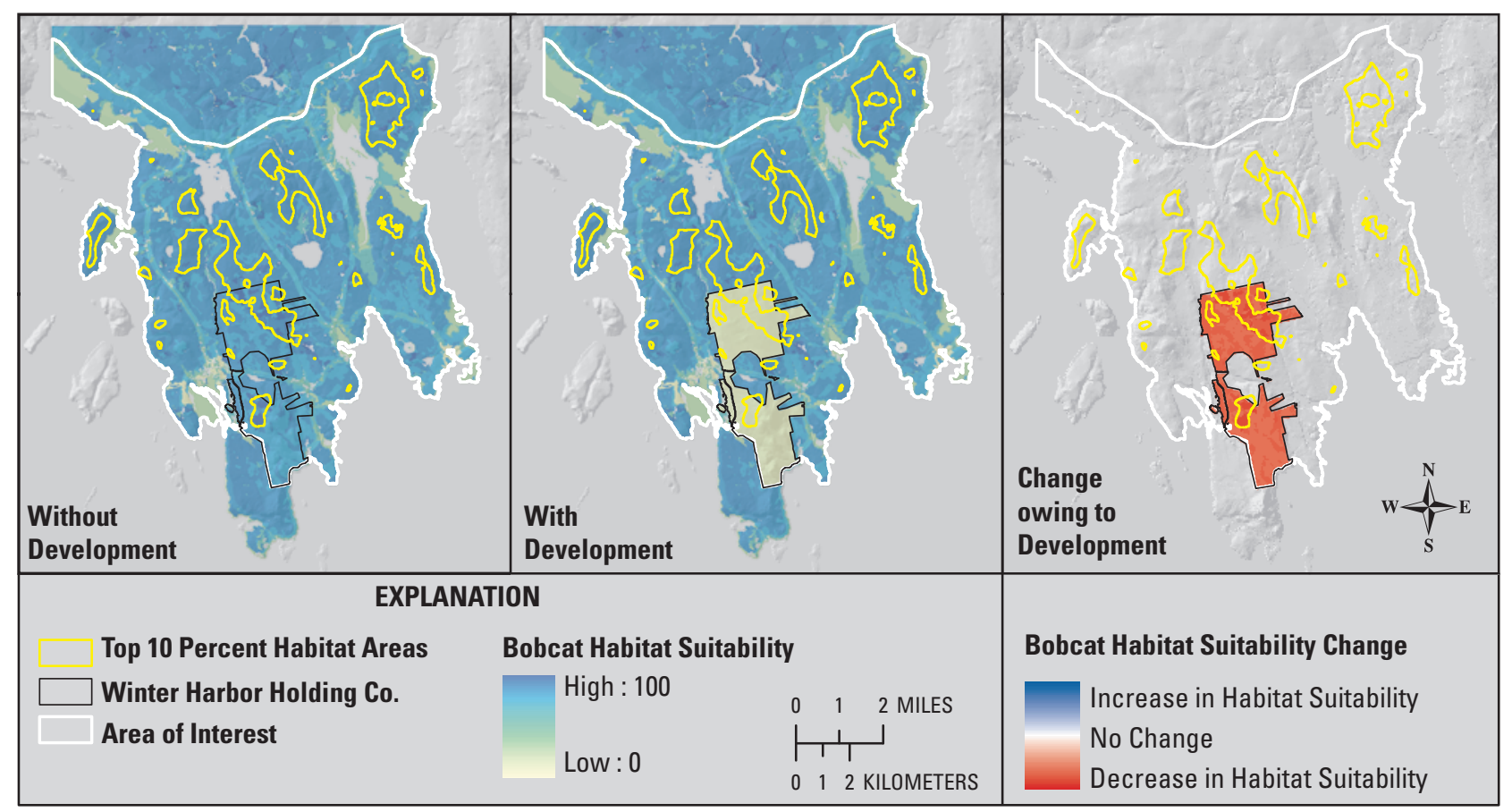

Figure 10. Habitat-suitability model results for bobcat without development of the Winter Harbor Holding Company (WHHC) parcel (left panel), with development (middle panel), and the change attributable to development of the WHHC parcel (right panel). Note the overlap of high-quality habitat patches (yellow outline) with the WHHC parcel (black outline) and subsequent change in habitat-suitability scores for those patches.

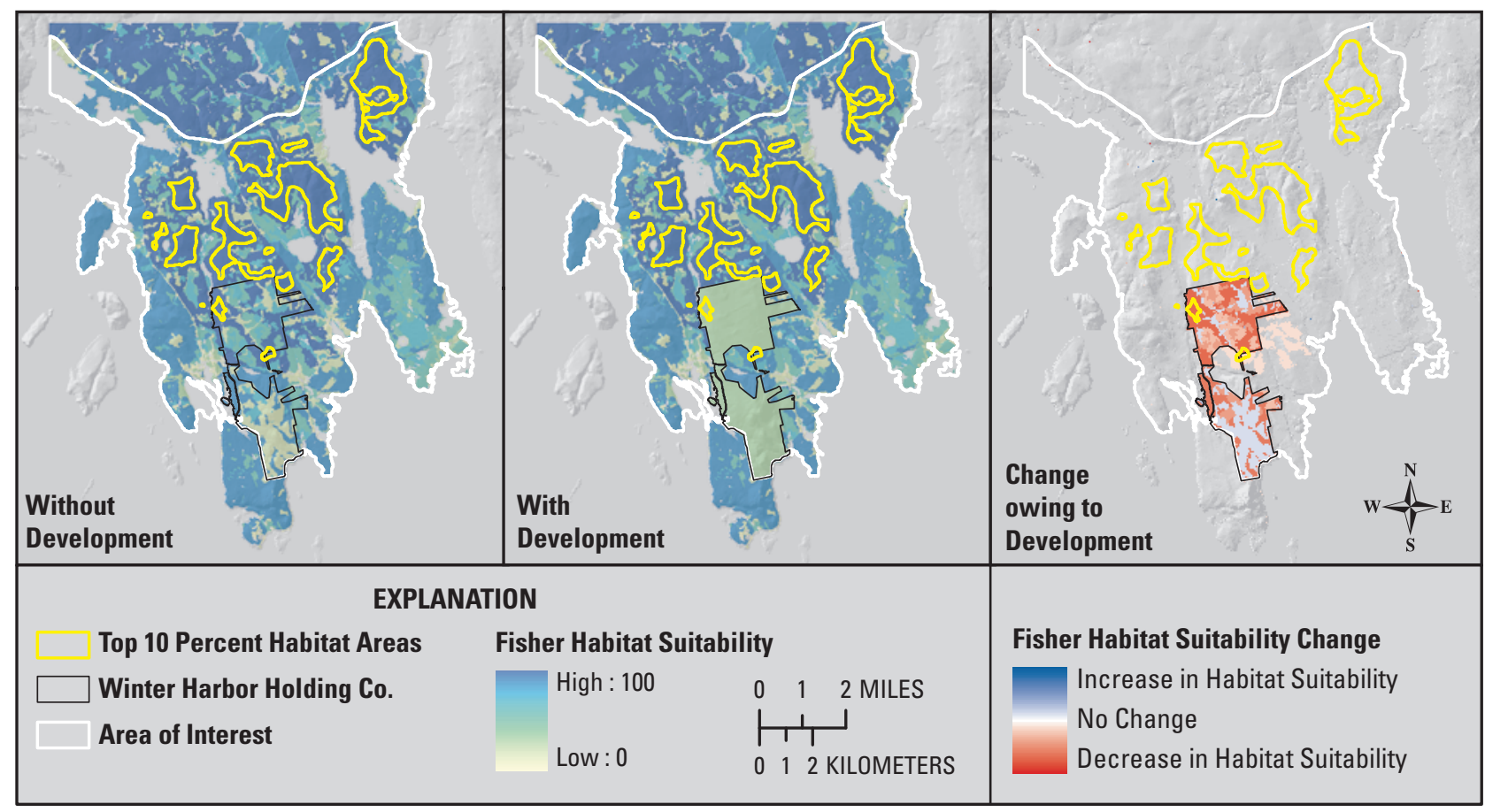

Figure 11. Habitat-suitability model results for fisher without development of the Winter Harbor Holding Company (WHHC) parcel (left panel), with development (middle panel), and the change attributable to development of the WHHC parcel (right panel). Note the relative lack of overlap of high-quality habitat patches (yellow outline) with the WHHC parcel (black outline). 


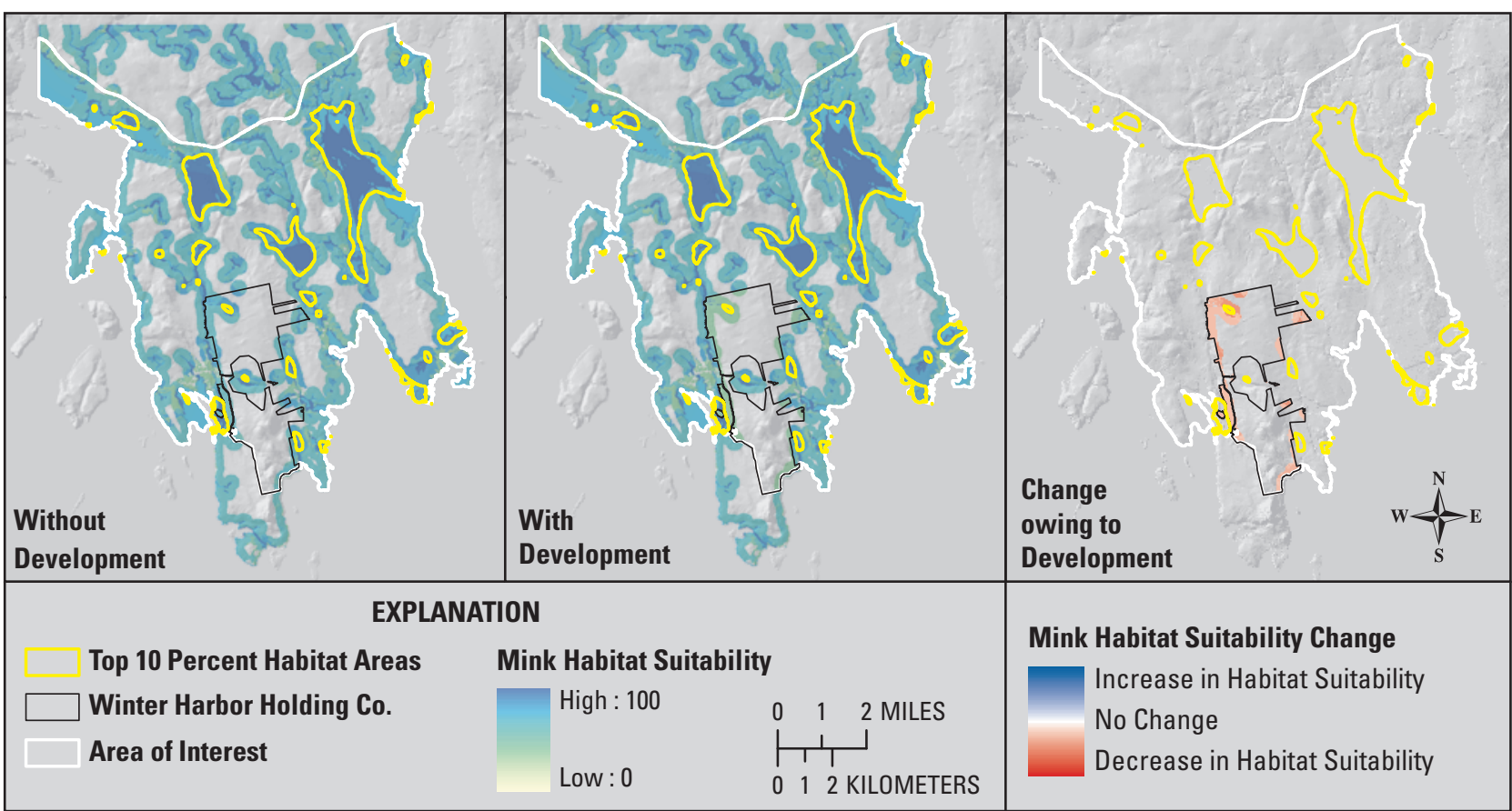

Figure 12. Habitat-suitability model results for mink without development of the Winter Harbor Holding Company (WHHC) parcel (left panel), with development (middle panel), and the change attributable to development of the WHHC parcel (right panel). As with fisher, high-quality habitat patches for mink overlapped very little with the WHHC parcel (black outline).

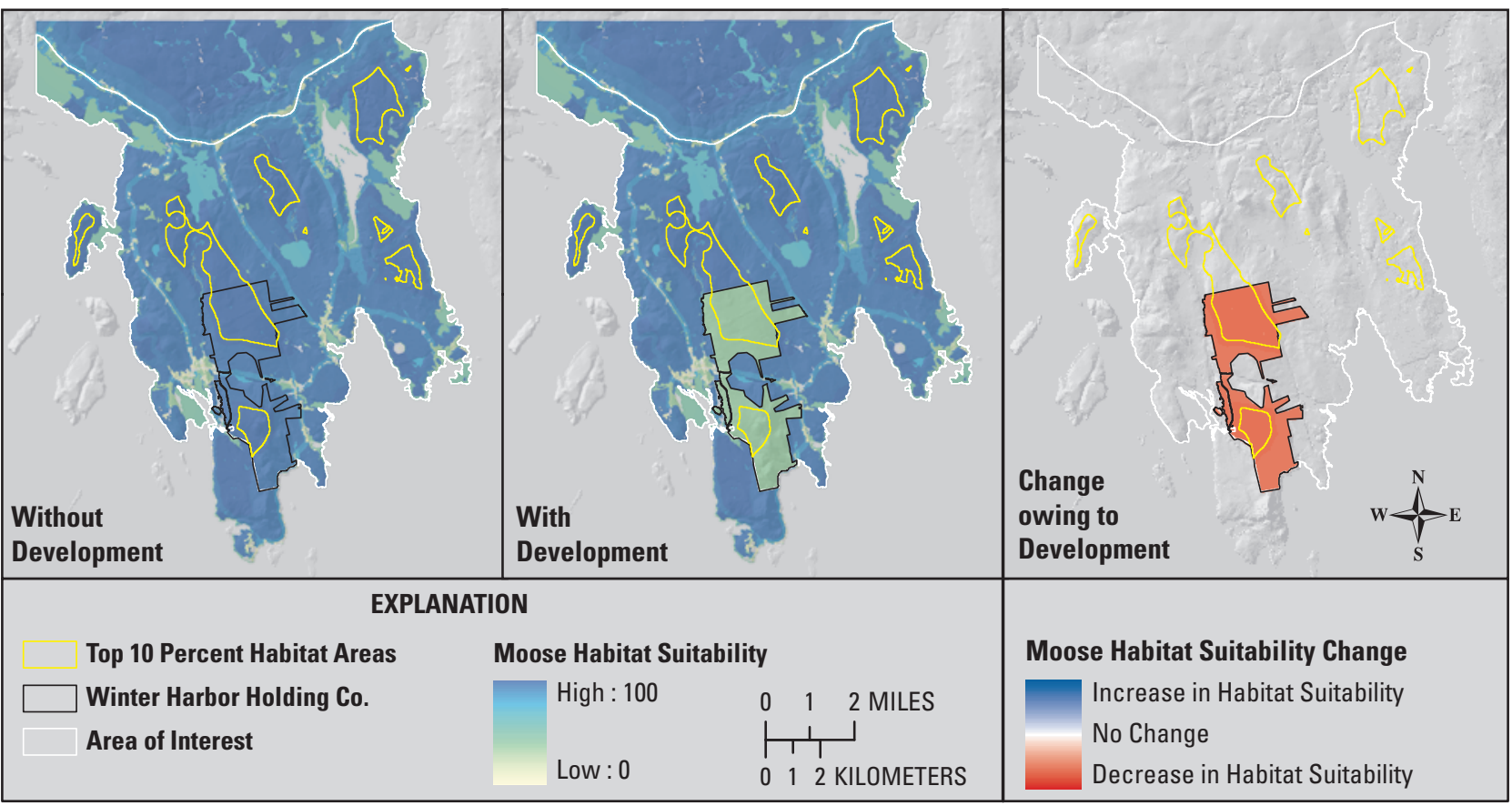

Figure 13. Habitat-suitability model results for moose without development of the Winter Harbor Holding Company (WHHC) parcel (left panel), with development (middle panel), and the change attributable to development of the WHHC parcel (right panel). Note the overlap of high-quality habitat patches (yellow outline) with the WHHC parcel (black outline) and subsequent change in habitat-suitability scores for those patches. The early successional forest habitat within the WHHC parcel is ideal for moose. 


\section{Least-Cost Corridor}

Changes to the suitability of habitat within the WHHC parcel had a large impact on the cost associated with movement of bobcat, fisher, and moose between the Schoodic District of the ANP and lands north of U.S. Highway 1 (table 5). Conversion of the WHHC parcel is predicted to increase the cost of movement associated with the entire AOI by approximately 37 percent for bobcat, 71 percent for fisher, and 63 percent for moose. Increases in the cost associated with movement through the WHHC parcel were approximately 105 percent for bobcat, 186 percent for fisher, 11 percent for mink, and 265 percent for moose. Lastly, the cost associated with movement through the high-quality patches of habitat increased by 50 percent for bobcat, 122 percent for fisher, and 140 percent for moose (table 5). The cost associated with movement for mink was least impacted by development because of the strong preference of mink for riparian areas and the lack of such areas within the WHHC parcel.

Table 5. Cost distance model-output values, by area of interest partitions, using high-quality habitat suitability areas north of U.S. Highway 1 and high-quality habitat suitability areas within the Schoodic District of Acadia National Park as source nodes.

\begin{tabular}{|c|c|c|c|c|}
\hline $\begin{array}{l}\text { Area of } \\
\text { interest } \\
\text { partition }\end{array}$ & Species & $\begin{array}{c}\text { Without } \\
\text { development }\end{array}$ & $\begin{array}{c}\text { With } \\
\text { development }\end{array}$ & $\begin{array}{c}\text { Percent } \\
\text { difference }\end{array}$ \\
\hline \multirow{4}{*}{$\begin{array}{l}\text { Entire area } \\
\text { of interest }\end{array}$} & Bobcat & 154,629 & 212,561 & 37.47 \\
\hline & Fisher & 70,484 & 120,579 & 71.07 \\
\hline & Mink & 138,436 & 139,338 & .65 \\
\hline & Moose & 38,713 & 63,004 & 62.75 \\
\hline \multirow{4}{*}{$\begin{array}{l}\text { Winter } \\
\text { Harbor } \\
\text { Holding } \\
\text { Company } \\
\text { parcel }\end{array}$} & Bobcat & 112,253 & 230,070 & 104.96 \\
\hline & Fisher & 48,317 & 138,375 & 186.39 \\
\hline & Mink & 76,753 & 84,932 & 10.66 \\
\hline & Moose & 23,958 & 87,334 & 264.54 \\
\hline \multirow{4}{*}{$\begin{array}{l}\text { High-quality } \\
\text { habitat } \\
\text { patches }\end{array}$} & Bobcat & 137,024 & 205,467 & 49.95 \\
\hline & Fisher & 36,475 & 81,050 & 122.21 \\
\hline & Mink & 122,612 & 123,353 & .60 \\
\hline & Moose & 31,840 & 76,375 & 139.87 \\
\hline
\end{tabular}

The changes in cost (owing to development) associated with movement through the WHHC parcel ultimately changed the most efficient travel routes for each species (figs. 14-18). Before development of the WHHC parcel, approximately 43 percent of the 10 percent least-cost corridor for bobcat overlapped the WHHC parcel as compared with only a 4 percent overlap following development of the WHHC parcel (figs. 14 and 15). The amount of the least-cost corridor overlapping the WHHC parcel for fisher declined from 16 to 1 percent (figs. 14 and 16), the overlap for mink declined from 10 to 6 percent (figs. 14 and 17), and the overlap for moose declined from 62 to less than 2 percent (figs. 14 and 18). These results reflect shifts in the most efficient travel routes between high-quality habitat suitability areas within the ANP and high-quality habitat suitability areas north of U.S. Highway 1, which may limit the ability of animals to travel into and out of the Schoodic District of the ANP.

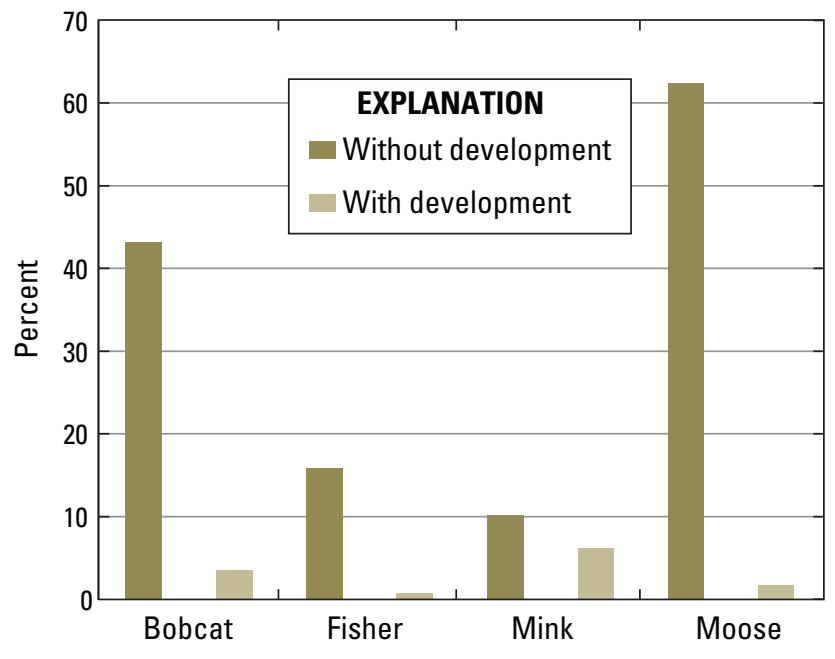

Figure 14. Results of the 10 percent least-cost corridor overlap with the Winter Harbor Holding Company parcel using as source nodes high-quality habitat suitability areas north of U.S. Highway 1 and high-quality habitat suitability areas within the Schoodic District of Acadia National Park to the south. 


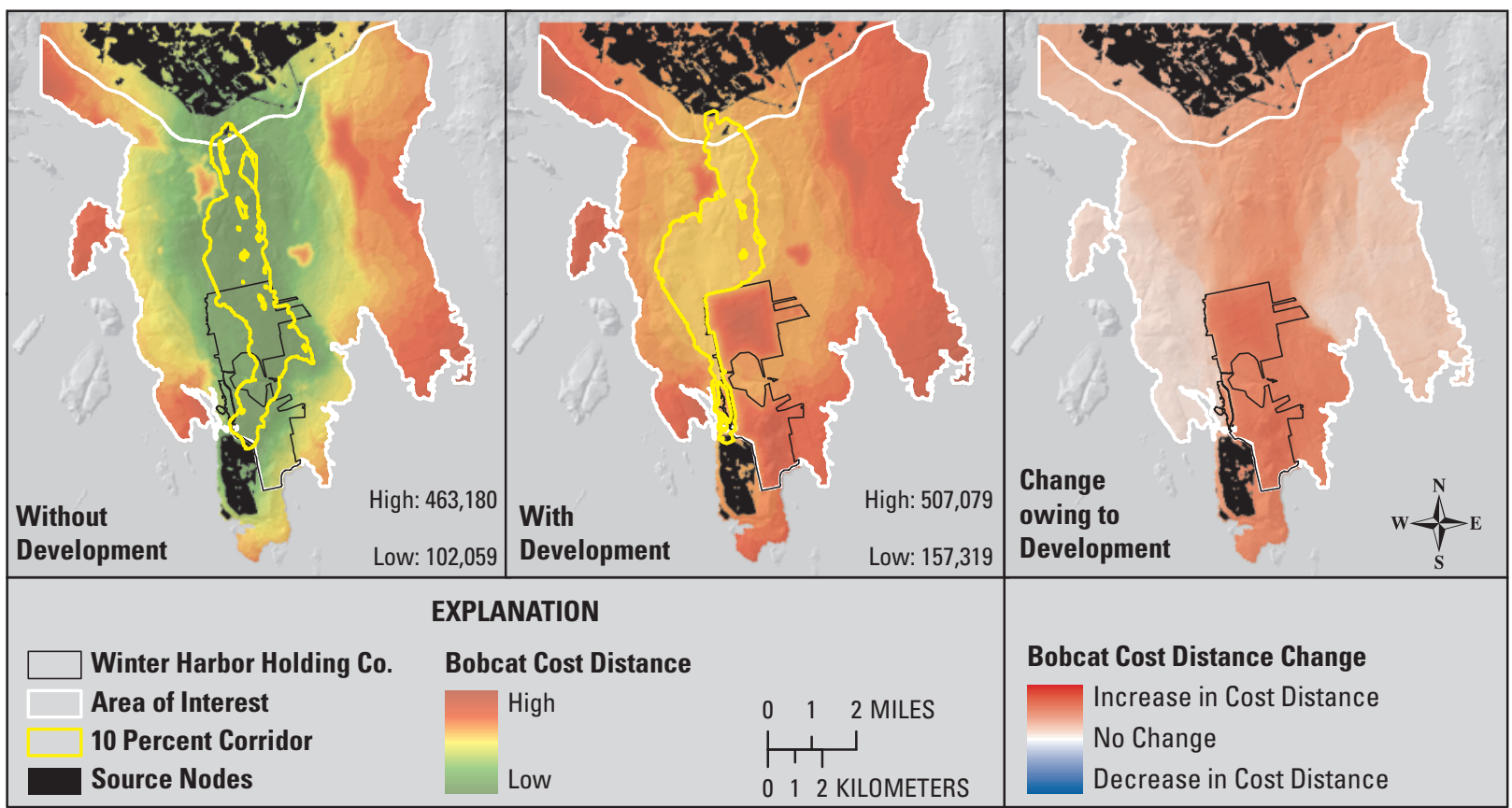

Figure 15. Cost associated with movement of bobcat between high-quality habitat suitability areas within Acadia National Park in the south (in black) and high-quality habitat suitability areas north of U.S. Highway 1 (also in black) without development of the Winter Harbor Holding Company (WHHC) parcel (left panel), with development (middle panel), and the change in cost attributable to development of the WHHC parcel (right panel). Development of the WHHC parcel would greatly increase the cost associated with movement of bobcat through the WHHC parcel and alter the least-cost corridor (yellow outline).

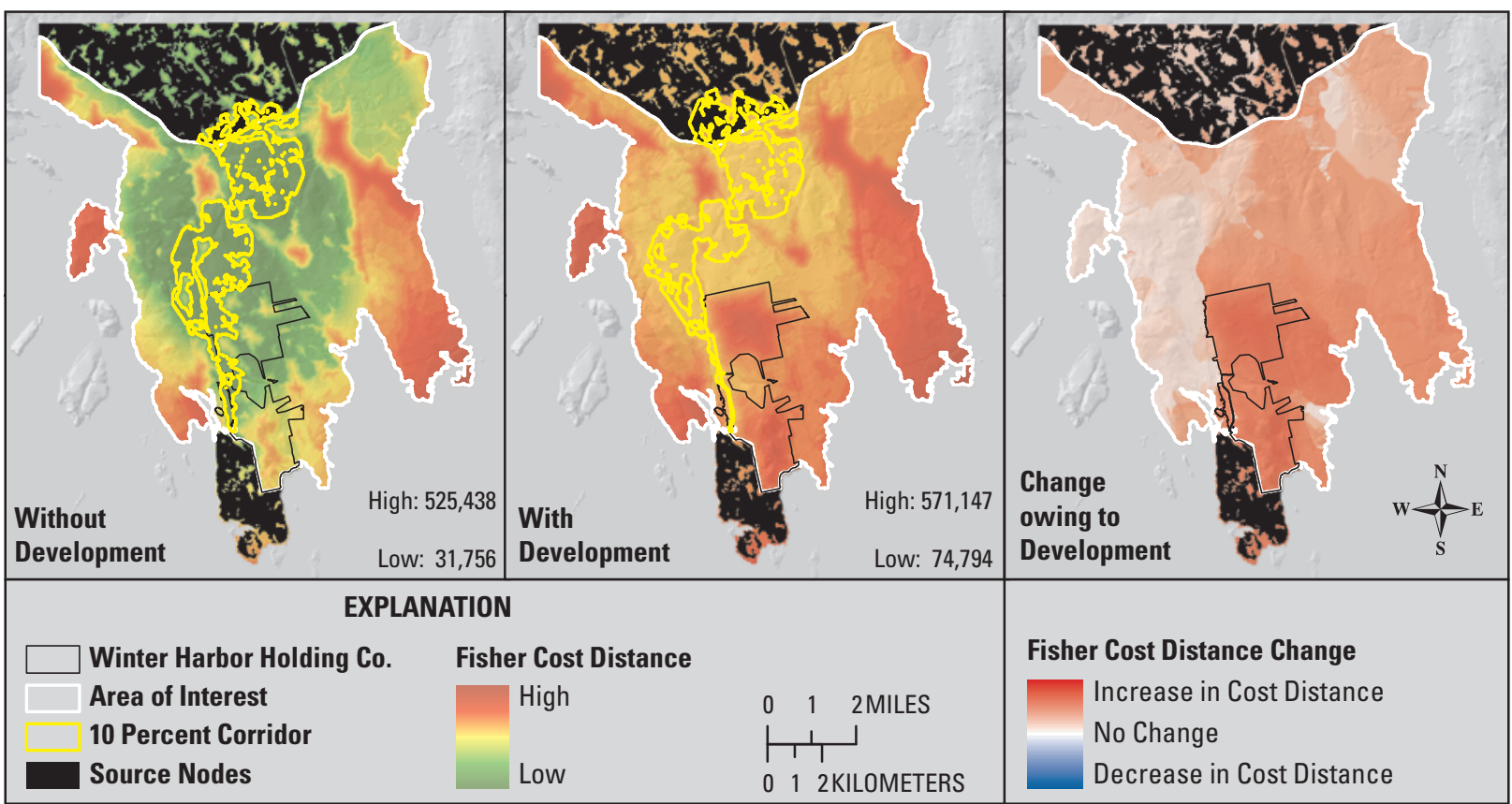

Figure 16. Cost associated with movement of fisher between high-quality habitat suitability areas within Acadia National Park in the south (in black) and high-quality habitat suitability areas north of U.S. Highway 1 (also in black) without development of the Winter Harbor Holding Company (WHHC) parcel (left panel), with development (middle panel), and the change in cost attributable to development of the WHHC parcel (right panel). Development of the WHHC parcel would increase the cost associated with movement of fisher through the WHHC parcel and alter the least-cost corridor (yellow outline) in the northern portion of the WHHC parcel as well as the northern portion of the peninsula. 


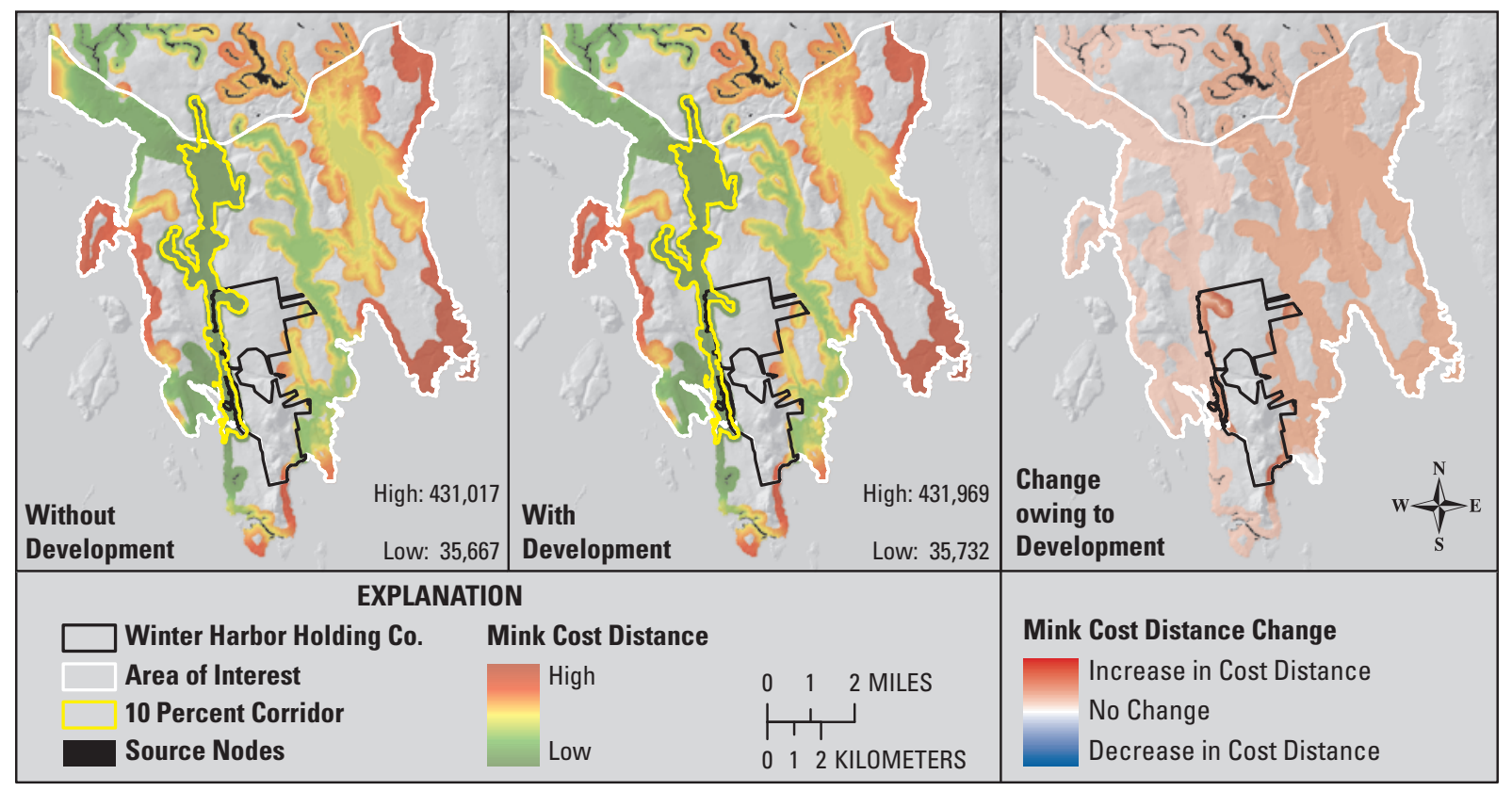

Figure 17. Cost associated with movement of mink between high-quality habitat suitability areas within Acadia National Park in the south (in black) and high-quality habitat suitability areas north of U.S. Highway 1 (also in black) without development of the Winter Harbor Holding Company (WHHC) parcel (left panel), with development (middle panel), and the change in cost attributable to development of the WHHC parcel (right panel). Development of the WHHC parcel would have minimal impact on the cost associated with movement of mink through the WHHC parcel and not alter the least-cost corridor (yellow outline). This is primarily a result of the high habitat preference of mink for riparian areas, which are not found in the WHHC parcel.

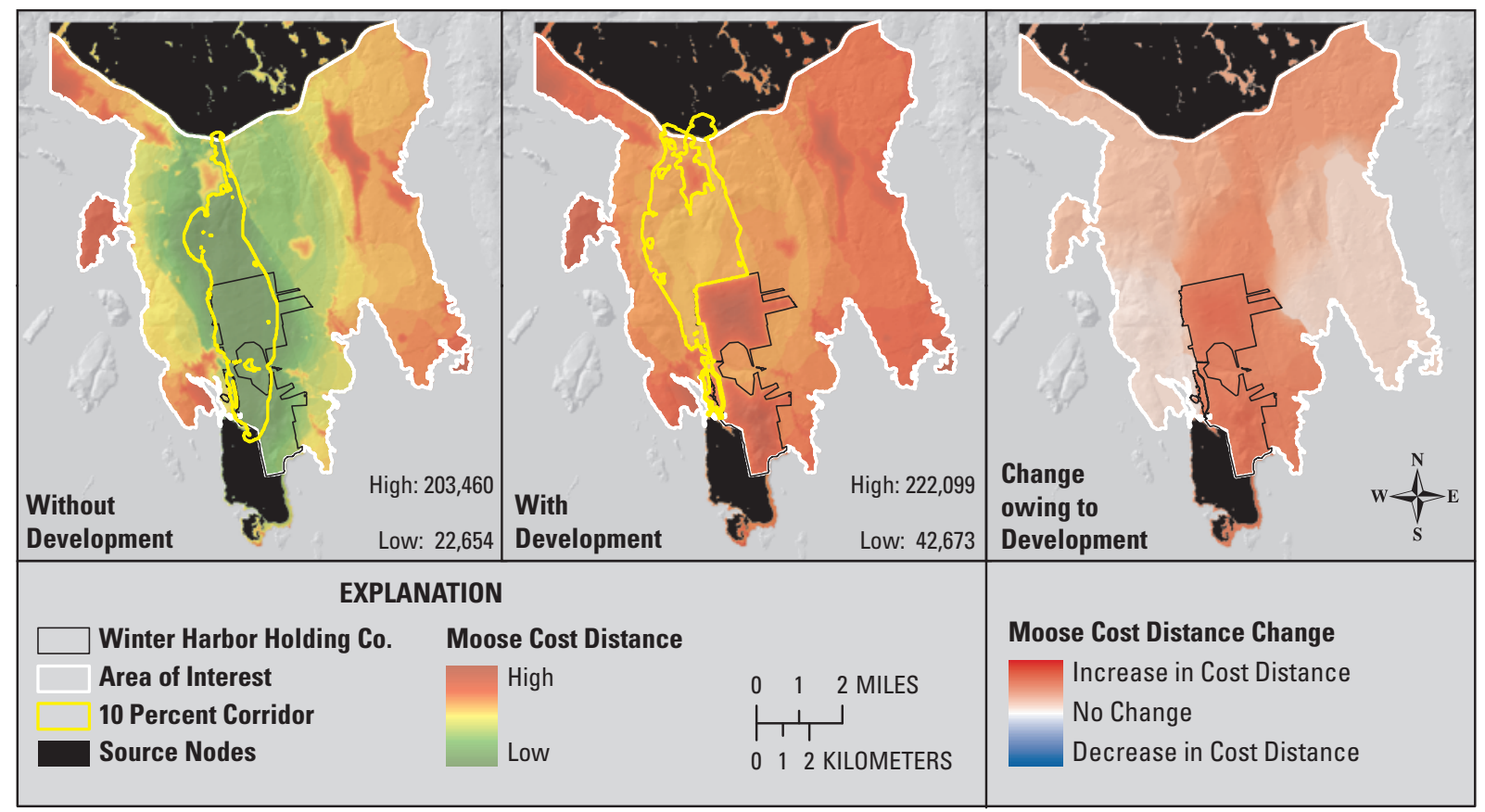

Figure 18. Cost associated with movement of moose between high-quality habitat suitability areas within Acadia National Park in the south (in black) and high-quality habitat suitability areas north of U.S. Highway 1 (also in black) without development of the Winter Harbor Holding Company (WHHC) parcel (left panel), with development (middle panel), and the change in cost attributable to development of the WHHC parcel (right panel). Development of the WHHC parcel would greatly increase the cost associated with moving moose through the parcel and alter the least-cost corridor (yellow outline). As indicated by the habitat-suitability analysis (fig. 13), the WHHC parcel is ideal habitat for moose. Conversion of this area would greatly impact the ability of moose to move between the Schoodic Unit of Acadia National Park and lands north of U.S. Highway 1. 


\section{Electrical Circuit Theory}

Estimates of effective resistance derived from electrical circuit theory also increased owing to development of the WHHC parcel, similar to the results based on the cost associated with animal movement between the Schoodic District of the ANP and lands north of U.S. Highway 1 (fig. 19). Effective resistance calculated across the entire Schoodic Peninsula increased by 74 percent for bobcat (from 0.0118 to 0.0206 ), 41 percent for moose (from 0.0093 to 0.0131 ), 19 percent for fisher (from 0.0179 to 0.0213 ), and 5 percent for mink (from 0.0399 to 0.0417 ). Given the strong preference of mink for riparian areas, this species had the highest effective resistance under the undeveloped scenario and was the least affected by development of the WHHC parcel.

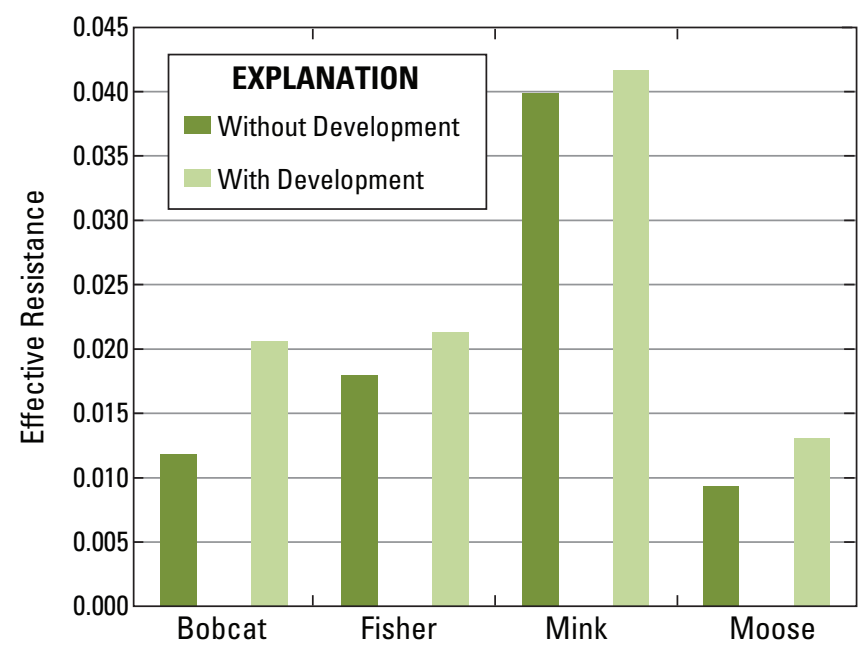

Figure 19. Differences in effective resistance between highquality habitat suitability areas within Acadia National Park and high-quality habitat suitability areas north of U.S. Highway 1 for bobcat, fisher, mink, and moose with and without development of the Winter Harbor Holding Company (WHHC) parcel. All species showed an increase in overall effective resistance with development of the WHHC parcel. Of particular note is the relative difficulty that mink are predicted to have moving from node to node under both scenarios as compared to the relative ease of movement for moose, bobcat, and fisher owing to their confinement to riparian corridor habitat.
Estimates of current density (the equivalent of the flow of charge through a cell within the landscape) can be mapped explicitly, whereas effective resistance is a single measure of the ease of movement from one node (Schoodic District of the ANP) to another node (lands north of U.S. Highway 1). Current density across the entire AOI was relatively unchanged following development of the WHHC parcel (table 6); however, current density changed greatly in some key areas (table 6 and figs. 20-23). For example, current density inside the WHHC declined by 32 percent for bobcat, 12 percent for fisher, 20 percent for mink, and 21 percent for moose, indicating that fewer animals are likely to move through the WHHC parcel following development. Current density through highquality habitat patches for bobcat and moose also declined in response to development of the WHHC parcel. These results are similar to those found for habitat-suitability scores within high-quality habitat, which declined most for moose and bobcat, given the high degree of overlap of some of these patches with the WHHC parcel.

Table 6. Changes to mean current density (the equivalent of the flow of charge through a cell on the landscape, or ease of animal movement) following development of the Winter Harbor Holding Company parcel as it relates to animals moving between the Schoodic District of Acadia National Park and lands north of U.S. Highway 1.

[Mean current density values have been multiplied by 10,000 in the table]

\begin{tabular}{ccccc}
\hline $\begin{array}{c}\text { Area of } \\
\text { interest } \\
\text { partition }\end{array}$ & Species & $\begin{array}{c}\text { Without } \\
\text { development }\end{array}$ & $\begin{array}{c}\text { With } \\
\text { development }\end{array}$ & $\begin{array}{c}\text { Percent } \\
\text { difference }\end{array}$ \\
\hline $\begin{array}{c}\text { Entire area } \\
\text { of interest }\end{array}$ & Bobcat & 10.16 & 10.42 & 2.60 \\
& Fisher & 9.63 & 9.78 & 1.57 \\
& Mink & 11.54 & 11.57 & .26 \\
\hline $\begin{array}{c}\text { Winter } \\
\text { Harbor }\end{array}$ & Boose & 9.86 & 10.02 & 1.59 \\
$\begin{array}{c}\text { Holding } \\
\text { pomparcel }\end{array}$ & 22.72 & 15.54 & -31.60 \\
& Fisher & 24.13 & 21.15 & -12.35 \\
& Mink & 8.85 & 7.05 & -20.32 \\
& Moose & 22.67 & 17.91 & -21.00 \\
\hline $\begin{array}{c}\text { High-quality } \\
\text { habitat } \\
\text { patches }\end{array}$ & Bobcat & 12.14 & 10.23 & -15.76 \\
& Fisher & 14.14 & 14.03 & -16.61 \\
\hline & Mink & 20.64 & 21.02 & 1.84 \\
\hline & 13.42 & 11.19 & -.76 \\
\hline
\end{tabular}




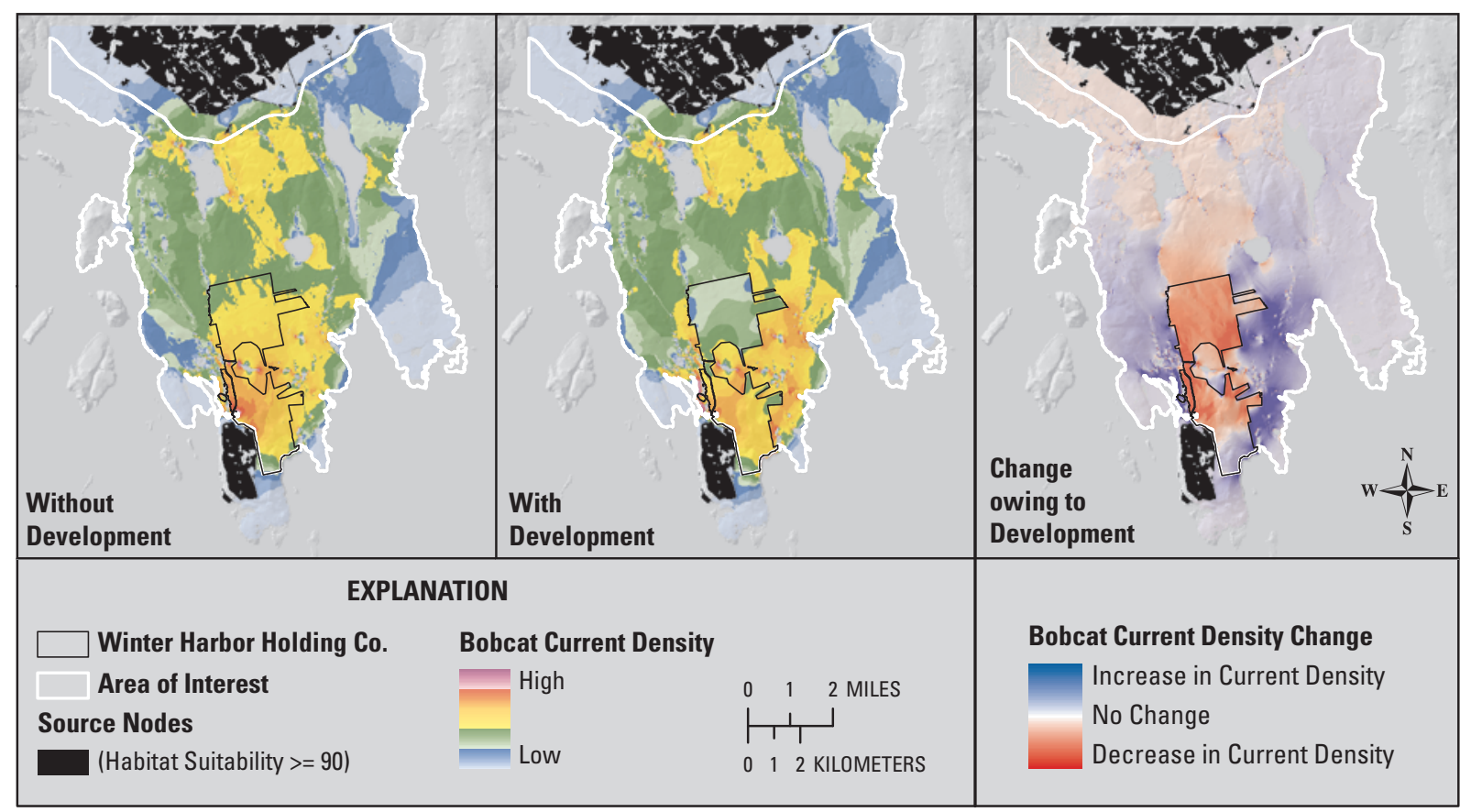

Figure 20. Changes to current density (a measure of the ease of animal movement) for bobcat between high-quality habitat suitability areas within Acadia National Park in the south (in black) and high-quality habitat suitability areas north of U.S. Highway 1 (also in black) owing to development of the Winter Harbor Holding Company (WHHC) parcel. Note the development of new "pinch points" (areas of extremely high current density) along the southeastern border of the WHHC parcel following development. As bobcat avoid the WHHC parcel (as indicated by the red areas in the change map, third panel) more animals are forecasted to move within a smaller portion of the landscape, as indicated by the pinch points.

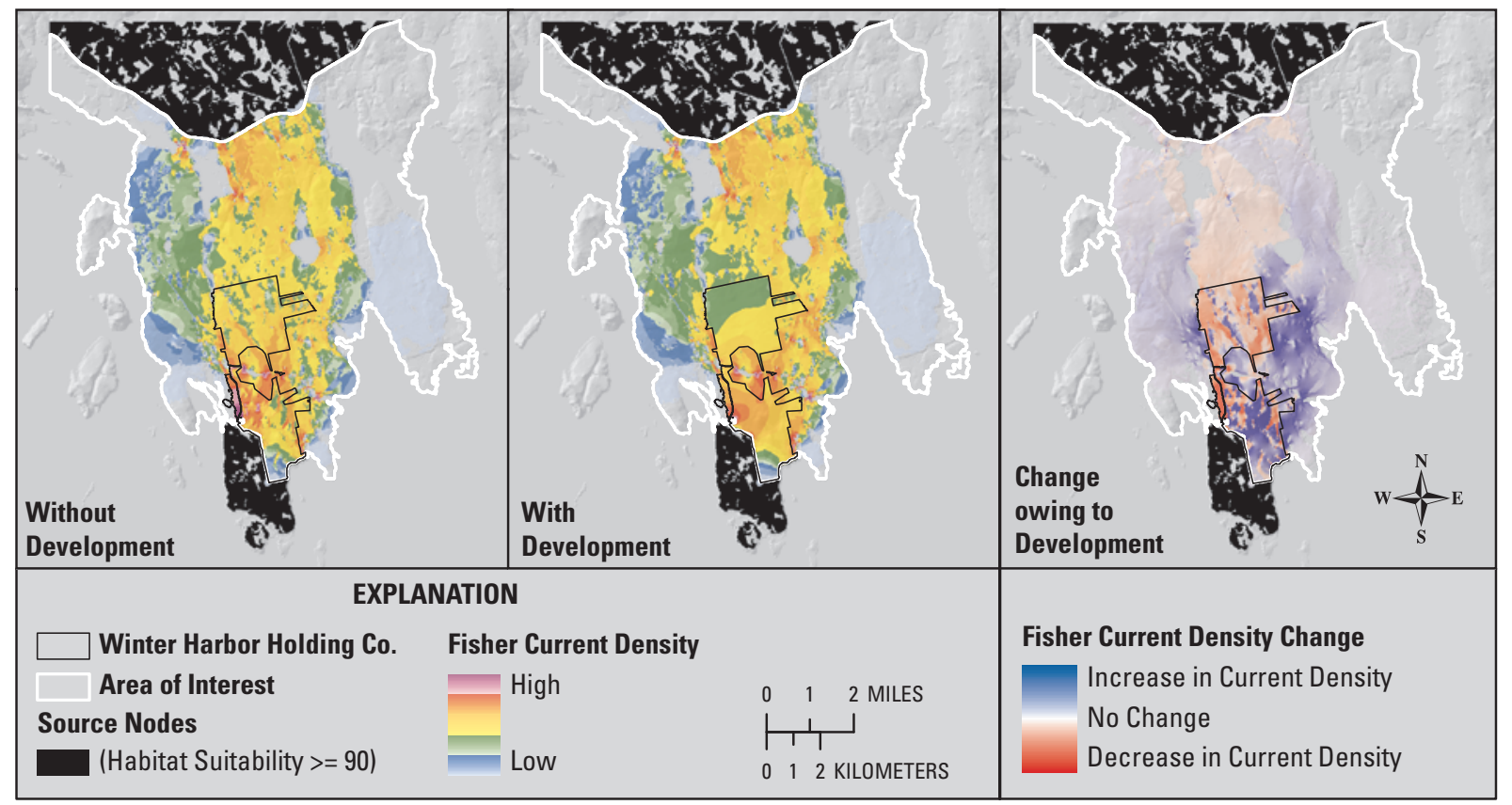

Figure 21. Changes to current density (a measure of the ease of animal movement) for fisher between high-quality habitat suitability areas within Acadia National Park in the south (in black) and high-quality habitat suitability areas north of U.S. Highway 1 (also in black) owing to development of the Winter Harbor Holding Company (WHHC) parcel. The greatest declines in current density were found within the southwest border of the WHHC parcel. Without development, this area is a pinch point for animal movement. With development, animals are forced to move through the southern portion of the WHHC parcel and toward the east. 


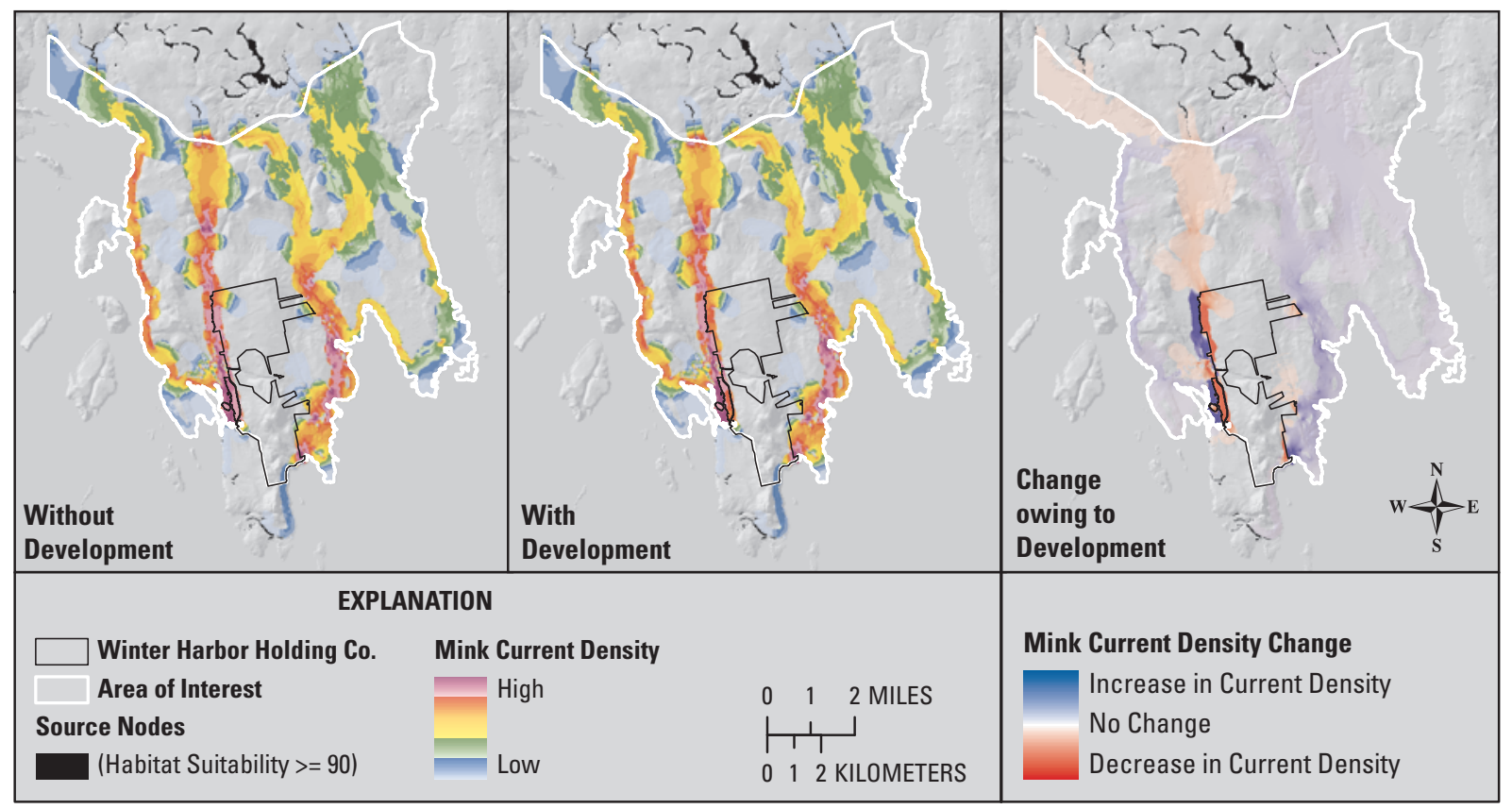

Figure 22. Changes to current density (a measure of the ease of animal movement) for mink between high-quality habitat suitability areas within Acadia National Park in the south (in black) and high-quality habitat suitability areas north of U.S. Highway 1 (also in black) owing to development of the Winter Harbor Holding Company (WHHC) parcel. Both with and without development, the highest current densities for mink were located along the eastern and western borders of the WHHC parcel. Following development, current density within the western border of the WHHC parcel decreased while current densities just outside the western and southeastern borders of the WHHC parcel increased. This indicates that, following development, more animals will be forced to move within a smaller portion of the Schoodic Peninsula. Also note the decline in current density north of the WHHC parcel.

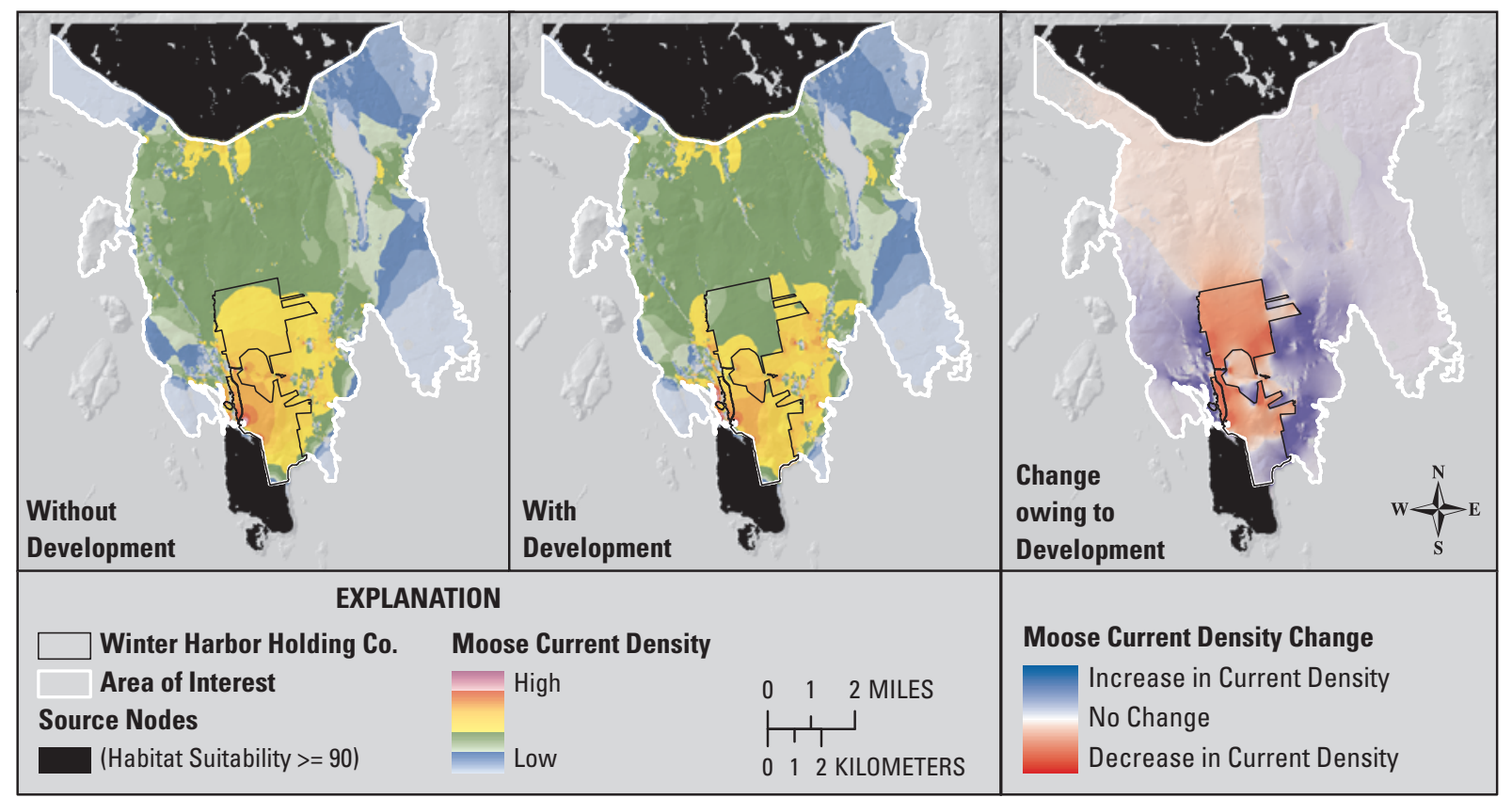

Figure 23. Changes to current density (a measure of the ease of animal movement) for moose between high-quality habitat suitability areas within Acadia National Park in the south (in black) and high-quality habitat suitability areas north of U.S. Highway 1 (also in black) owing to development of the Winter Harbor Holding Company (WHHC) parcel. Development of the WHHC parcel would lead to substantial decreases in current density within the WHHC parcel (red areas in right panel) for moose and likely lead to more animals dispersing along the eastern and western borders of the WHHC parcel. Thus, more animals would be forced to move across a smaller portion of the Schoodic Peninsula following development of the WHHC parcel. 
As a result of the decreased current density within the WHHC parcel following development, current densities in other areas of the Schoodic Peninsula increased, indicating that more animals are expected to use alternative routes to travel between the ANP and lands north of U.S. Highway 1 (figs. 20-23) following development. For bobcat (fig. 20) and moose (fig. 23) development of the WHHC parcel would lead to substantial decreases in current density within the WHHC parcel (table 6), and this would lead to increases in current density and the development of "pinch points" (areas of extremely high current density) just outside of the eastern and western borders of the WHHC parcel (figs. 20 and 23). The development of pinch points in these locations indicates that moose and bobcat are likely to be forced to disperse within a much smaller portion of the Schoodic Peninsula in order to move between the ANP and lands north of U.S. Highway 1.

Although current densities are forecasted to decrease much less for fisher than for bobcat and moose following development of the WHHC parcel (table 6), we detected potentially important changes to the ease of movement for this species (fig. 21). Under the current, undeveloped scenario, a pinch point exists within the southwestern border of the WHHC parcel. Development decreased current density in this area and increased current density across a broader portion of the WHHC parcel in the southeastern region. These results indicate that more animals are likely to disperse through the southeastern portion of the WHHC parcel than currently do so because movement through the southwestern portion of the WHHC parcel may become restricted.

The most likely travel routes for mink between the Schoodic District of the ANP and lands north of U.S. Highway 1 were similar when identified by least-cost path analysis (fig. 17) and electrical circuit theory (fig. 22), regardless of the analysis type; development of the WHHC parcel did not significantly alter these routes on a broad scale. However, current densities for mink did change owing to development at finer scales in some key locations (fig. 22). For example, current densities declined within the western border of the WHHC parcel and increased just outside of the parcel following development. This indicates that animals likely will disperse outside of the WHHC parcel rather than inside the parcel following development. As was the case for bobcat and moose, such changes indicate that more animals will be forced to move within a smaller portion of the Schoodic Peninsula following development of the WHHC parcel.

Throughout this study, we assumed that the entire 1,295 ha of the WHHC parcel would be converted to "developed-open space." We made this assumption because we did not have information regarding the likely locations within the WHHC parcel where development may or may not occur. However, our analysis may assist in identifying high-priority conservation areas within the WHHC parcel. For example, figure 24 shows the change in cumulative current density summed across all four species in this study. Although current density decreased in nearly all portions of the map (fig. 24), indicating that the flow of animals into and out of the ANP likely will be reduced by development of the WHHC parcel, a few areas of relatively high current density (pinch points) remain along the southwestern and southeastern corners of the WHHC parcel. These areas appear in shades of red in the center panel of figure 24. This indicates that, following development of the WHHC parcel, animal movement likely will be restricted to very small corridors along the southeastern and southwestern corners of the WHHC parcel. Furthermore, the strongest decline in current density occurred along the western border of the WHHC parcel (represented in green in the right map panel of fig. 24), indicating that conversion of this area to developed-open space will have the largest effect on animal movement to and from the ANP. Therefore, this area may be a high priority area for conservation under the assumption that the entire WHHC parcel is converted to developed-open space. 


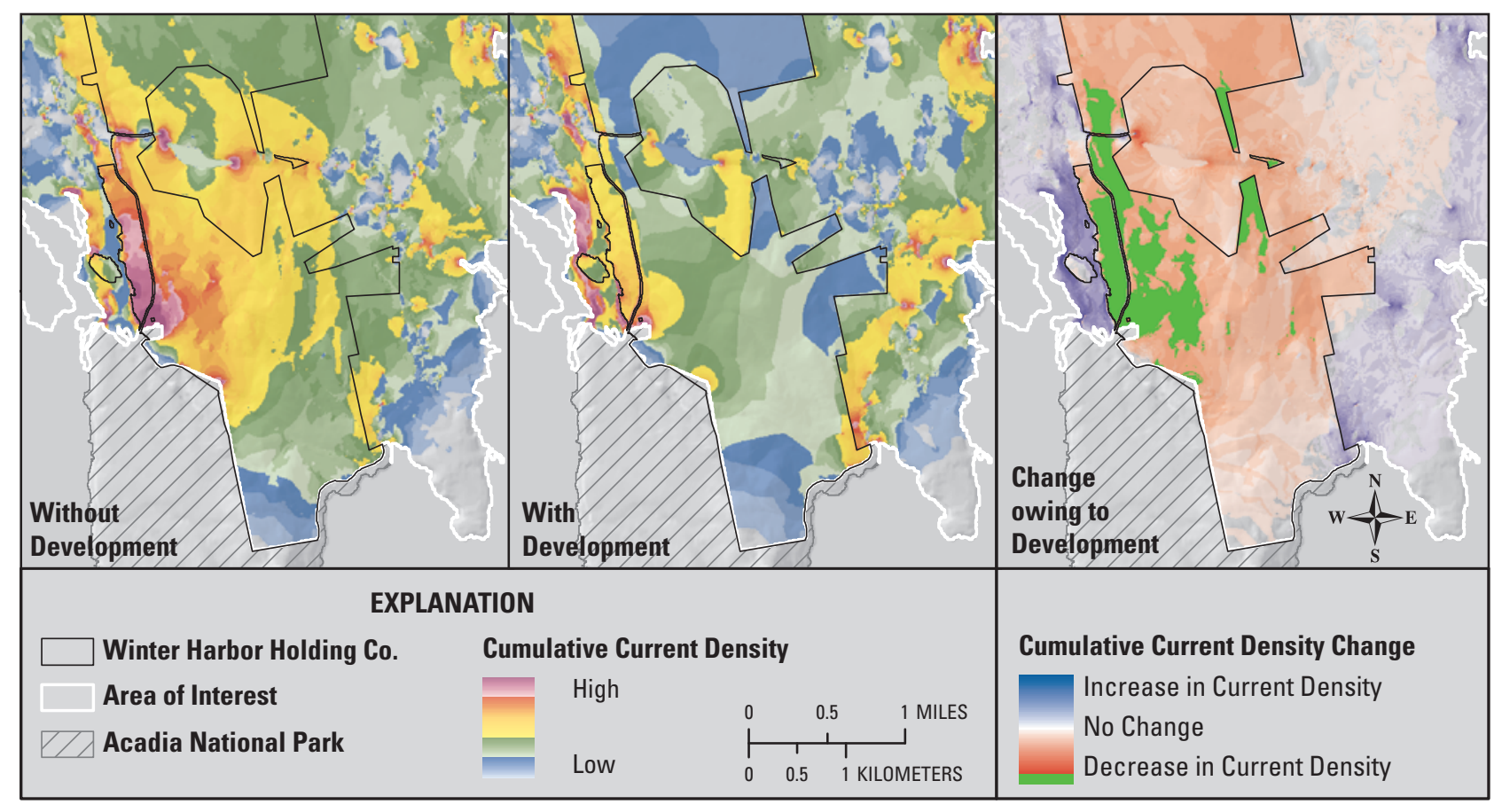

Figure 24. Changes to cumulative current density at the northern border of Acadia National Park summed across all four species (bobcat, fisher, mink, and moose) before and after development of the Winter Harbor Holding Company (WHHC) parcel. Development of the WHHC parcel would cause a decrease in current density in most portions of the map and force animal movement into a few small corridors along the southeastern and southwestern corners of the WHHC parcel. Areas in the right panel of the map (shaded green) represent the areas within the WHHC parcel with the greatest decrease in current density (top 5 percent). 


\section{Conclusions}

The planned 1,295 hectare Winter Harbor Holding Company (WHHC) parcel development would likely lead to (1) increased edge effects that may propagate into the natural habitat found within the Schoodic District of Acadia National Park (ANP); (2) substantial decreases in habitat suitability for bobcat, fisher, mink, and moose within the WHHC parcel and across the entire Schoodic Peninsula for bobcat and moose; and (3) increases in the cost associated with movement of bobcat, fisher, and moose as well as impeding the most efficient and important travel routes between high-quality habitat suitability areas within the Schoodic District of the ANP and high-quality habitat suitability areas north of U.S. Highway 1 for bobcat, fisher, and moose.

From the analysis of core and interior natural habitat, we found that development of the WHHC parcel led to 1.4 to 8.7 times more loss in the percentage of habitat meeting the criterion for core (completely unfragmented) and interior $(<10$ percent fragmented) across the entire area of interest as compared to the direct loss of natural habitat alone. Furthermore, although development of the WHHC parcel would result in no change in the total amount of natural habitat within the ANP, the increased edge created by development of the WHHC parcel could extend well into the ANP boundary. Reclassifying the WHHC parcel to developed within the models and analyses used led to greater declines in interior natural habitat found within the ANP boundary. These results represent a shift in the remaining natural habitat from core (completely unfragmented) and interior (only slightly fragmented) to habitat that suffers from substantial edge effects. Finally, the effects of development of the WHHC parcel on core and interior natural habitat both across the entire Schoodic Peninsula and within the ANP boundary increased as we increased the scale of our analysis (window size). The implications of these results may include (1) reduced habitat suitability, especially for species with large home ranges that require large blocks of uninterrupted habitat; (2) higher rates of atmospheric deposition along newly created patch edges (Weathers and others, 2001); (3) a higher probability of invasion by exotic species (Harper and others, 2005); and (4) fewer shade-tolerant plant species (Foster and others, 1998).

From the habitat-suitability, least-cost corridor, and electrical circuit theory analyses, we learned that the WHHC parcel is of high quality for bobcat, fisher, mink, and moose. Both bobcat and moose had patches of high-quality habitat (top 10 percent of habitat suitability) within the WHHC parcel. Furthermore, reclassification of the WHHC parcel as developed led to declines in the suitability of habitat found within the WHHC parcel for all four species and changed likely movement patterns as well. For example, the cost associated with movement between high-quality habitat areas within the
ANP and high-quality habitat areas north of U.S. Highway 1 increased following development of the WHHC parcel for bobcat, fisher, and moose, and the least-cost corridor for these species shifted away from the WHHC parcel. These results indicate that animals are likely to take less preferred and less suitable travel routes to and from the Schoodic District of the ANP following development of the WHHC parcel. The increased resistance to animal movement found here may ultimately reduce animal movement into and out of the ANP. Although it is unclear whether reduced animal movement into and out of the ANP would result in the break-up and isolation of animal populations, it seems likely that it will restrict access to the ANP for some animals, reducing wildlife viewing opportunities for the ANP visitors. It also is possible that reduced movement out of the ANP by moose could lead to overbrowsing and declines in plant growth, survival, and biodiversity.

\section{References Cited}

Arnold, T.W., and Fritzell, E.K., 1990, Habitat use by male mink in relation to wetland characteristics and avian prey abundances: Canadian Journal of Zoology, v. 68, no. 10, p. 2205-2208.

Arthur, S.M., Krohn, W.B., and Gilbert, J.R., 1989, Home range characteristics of adult fishers: The Journal of Wildlife Management, v. 53, no. 3, p. 674-679.

Beginning with Habitat [n.d.a], Request Digital GIS data for a town or region in Maine, accessed June 6, 2011, at http:// $w w w$. beginningwithhabitat.org/the_maps/gis_data_request. html.

Beginning with Habitat [n.d.b], Focus areas of statewide ecological significance-Schoodic Peninsula, accessed October 13, 2011, at www.maine.gov/doc/nrimc/mnap/ focusarea/schoodic_peninsula_focus_area.pdf.

Buechner, M.C., Schonewald-Cox, R. S., and Wilcox, B.A., 1992, Crossboundary issues for national parks-What works "on the ground:" Environmental Management, v. 16, p. 799-809.

DeGraaf, R.M., and Yamasaki, M., 2001, New England wildlife-Habitat, natural history, and distribution: Hanover, N.H., University Press of New England, 482 p.

De Jager, N.R., and Pastor, J., 2009, Declines in moose population density at Isle Royale National Park, MI, USA, and accompanied changes in landscape patterns: Landscape Ecology, v. 24, p. 1389-1403. 
De Jager, N.R., Pastor, J., and Hodgson, A.L., 2009, Scaling the effects of moose browsing on forage distribution from plant canopies to landscapes: Ecological Monographs, v. 79, no. 2, p. 281-297.

Foster, D.R., Motzkin, G., and Slater, B., 1998, Land-use history as long-term broad-scale disturbance-Regional forest dynamics in central New England: Ecosystems, v. 1, p. 96-119.

Harper, K.A., MacDonald, S.A., Burton, P.J., Chen, J., Brosofske, K.D., Saunders, S.C., Euskirchen, E.S., Roberts, D., Jaiteh, M.S., and Esseen, P-A., 2005, Edge influence on forest structure and composition in fragmented landscapes: Conservation Biology, v. 19, p. 768-782.

Kupfer, J.A., 2006, National assessments of forest fragmentation in the US: Global Environmental Change, v. 16, p. 73-82.

Langen, T.A., Ogden, L., and Schwarting, L., 2009, Predicting hotspots of herpetofauna road mortality along highway networks: Journal of Wildlife Management, v. 73, p. 104-114.

Laurance, W.F., Lovejoy, T.E., Vasconcelos, H.L., Burna, E.M., Didham, R.K., Stouffer, P.C., Gascon, C., Bierregaard, R.O., Laurance, S.G., and Sampaio, E., 2002, Ecosystem decay of Amazonian forest fragments - A 22-year investigation: Conservation Biology, v. 16, p. 605-618.

Leptich, D.J., and Gilbert, J.R., 1989, Summer home range and habitat use by moose in northern Maine: The Journal of Wildlife Management, v. 53, no. 4, p. 880-885.

Lindenmayer, D.B., and Franklin, J.F., 2002, Conserving forest biodiversity-A comprehensive multiscaled approach: Washington, D.C., Island Press, 351 p.

Maine Office of Geographic Information Systems (MEGIS), [n.d.], Landcover-MELCD 2004 (MELCD), accessed October 3, 2011, at http://geolibportal.usm.maine.edu/ geonetwork/srv/en/metadata.show? id $=427$.

Majka, D., Jenness, J., and Beier, P., 2007, CorridorDesigner-ArcGIS tools for designing and evaluating corridors. Available at http://corridordesign.org.

McRae, B.H., 2006, Isolation by resistance: Evolution, v. 60, p. 1551-1561.

McRae, B.H., and Beier, P., 2007, Circuit theory predicts gene flow in plant and animal populations: Proceedings of the National Academy of Sciences, v. 104, p. 19885-19890.

McRae, B.H., Dickson, B.G., Keitt, T.H., and Shah, V.B., 2008, Using circuit theory to model connectivity in ecology and conservation: Ecology, v. 10, p. 2712-2724.
McRae, B.H., and Shah, V.B., 2009, Circuitscape user's guide_-Online: Santa Barbara, Calif., University of California. Available at http://www.circuitscape.org/Circuitscape/ User_Guide.html.

National Park Service, 2006, Management policies: Washington, D.C., U.S. Government Printing Office, 168 p.

Pinto, Naiara, and Keitt, T.H., 2008, Beyond the least-cost path-Evaluating corridor redundancy using a graph-theoretic approach: Landscape Ecology, v. 24, no. 2, p. 253-266.

Ramaharitra, Tendro, 2006, The effects of anthropogenic disturbances on the structure and composition of rainforest vegetation: Tropical Resources Bulletin, v. 25, p. 32-37.

Riitters, K.H., O’Neill, R.V., and Jones, K.B., 1997, Assessing habitat suitability at multiple scales-A landscape-level approach: Biological Conservation, v. 81, nos. 1-2, p. 191-202.

Riitters, K.H., Wickham, J.D., O’Neill, R.V., Jones, K.B., and Smith, E.R., 2000, Global-scale patterns of forest fragmentation: Conservation Ecology, v. 4, no. 2, art. 3. Available at http://www.consecol.org/vol4/iss2/art3/.

Riitters, K.H., Wickham, J.D., O’Neill, R.V., Jones, K.B., Smith, E.R., Coulston, J.W., Wade, T.G., and Smith, J.H., 2002, Fragmentation of continental United States forests: Ecosystems, v. 5, p. 815-822.

Shands, W.E., 1979, Federal resource lands and their neighbors: Washington, D.C., Conservation Foundation, 98 p.

Tischendorf, L., and Fahrig, L., 2000, On the usage and measurement of landscape connectivity: Environmental Management, v. 90, p. 7-19.

Walker, Richard, and Craighead, Lance, 1997, Analyzing wildlife movement corridors in Montana using GIS, in Proceedings of the 1997 ESRI International User Conference, San Diego, Calif., July 8-11, 1997. Available at http:// proceedings.esri.com/library/userconf/proc97/proc97/ to150/pap116/p116.htm.

Weathers, K.C., Cadenasso, M.L., and Pickett, S.T.A., 2001, Forest edges as nutrient and pollutant concentrators-Potential synergisms between fragmentation, forest canopies, and the atmosphere: Conservation Biology, v. 15, p. 1506-1514.

Wickham, J.D., Riitters, K.H., Wade, T.G., and Coulston, J.W., 2007, Temporal change in forest fragmentation at multiple scales: Landscape Ecology, v. 22, p. 481-489.

Wilcox, B.A., and Murphy, D.D., 1985, Conservation strategy-The effects of fragmentation on extinction: American Naturalist, v. 125, p. 879-887. 
World Conservation Monitoring Centre, 1992, Global biodiversity-Status of the Earth's living resources: New York, Chapman and Hall, 585 p.

Zube, E.H., 1995, Greenways and the U.S. National Park System: Landscape and Urban Planning, v. 33, p. 17-25.
Zuidema, P.A., Sayer, J.A., and Dijkman, W., 1996, Forest fragmentation and biodiversity-The case for intermediatesized conservation areas: Environmental Conservation, v. 23, p. 290-297. 

